\title{
TUNING ELECTROSPINNING PARAMETERS FOR PRODUCTION OF 3D-FIBER- FLEECES WITH INCREASED POROSITY FOR SOFT TISSUE ENGINEERING APPLICATIONS
}

\author{
Vincent Milleret ${ }^{1}$, Benjamin Simona ${ }^{1}$, Peter Neuenschwander ${ }^{2}$ and Heike Hall ${ }^{1 *}$ \\ ${ }^{1}$ Cells and Biomaterials, Department of Materials, ETH Zurich, Switzerland \\ ${ }^{2}$ ab medica spa, Lainate, Italy
}

\begin{abstract}
Degrapol $^{\circledR}$ and PLGA electrospun fiber fleeces were characterized with regard to fiber diameter, alignment, mechanical properties as well as scaffold porosity. The study showed that electrospinning parameters affect fiber diameter and alignment in an inverse relation: fiber diameter was increased with increased flow rate, with decrease in working distance and collector velocity, whereas fiber alignment increased with the working distance and collector velocity but decreased with increased flow rate. When Degrapol $^{\circledR}$ or PLGA-polymers were co-spun with increasing ratios of a water-soluble polymer that was subsequently removed; fibrous scaffolds with increased porosities were obtained. Mechanical properties correlated with fiber alignment rather than fiber diameter as aligned fiber scaffolds demonstrated strong mechanical anisotropy. For co-spun fibers the Young's modulus correlated inversely with the amount of co-spun polymer. Cell proliferation was independent of the porosity of the scaffold, but different between the two polymers. Furthermore, fibrous scaffolds with different porosities were analyzed for cell infiltration suggesting that cell infiltration was enhanced with increased porosity and increasing time. These experiments indicate that 3D-fiber fleeces can be produced with controlled properties, being prerequisites for successful scaffolds in tissue engineering applications.
\end{abstract}

Keywords: Degrapol ${ }^{\circledR}$, PLGA, 3D-fiber fleeces, cell infiltration, electrospinning, tissue engineering.

*Address for correspondence:

Heike Hall

ETH Zurich, Department of Materials, HCI E415

Cells and BioMaterials

Wolfgang-Pauli-Strasse 10

CH-8093 Zürich, Switzerland

Telephone Number: +41446336975

FAX Number: +41 446321073

E-mail: heike.hall@mat.ethz.ch

\section{Introduction}

Electrospinning is considered as the most efficient technique for micro- and nanofiber production and one of the few processes to produce polymeric fibers in large scale (Andrady, 2008). Many applications are related to the biomedical field. Particularly, electrospun polymeric fibers were employed for the production of scaffolds for vascular tissue engineering (Boland et al., 2004; Sell et al., 2009; McClure et al., 2011) or hollow organ substitutes such as bladder, trachea and esophagus (Baker et al., 2006; Chen et al., 2006; Brizzola et al., 2009; Leong et al., 2009). Although requirements for medical scaffolds are numerous and vary with every application, some of them are fulfilled by the processing technique itself (Mano et al., 2007). The architecture of the fibrous scaffold produced by electrospinning displays a high surface area for initial cell attachment, porosity for improved cell infiltration and nutrition diffusion thus providing some key features of the native extracellular matrix.

Bio-compatibility and -degradability as well as mechanical properties depend on the material composing the scaffolds (Andrady, 2008). Hence, for producing scaffolds for tissue engineering applications it is crucial to control electrospinning parameters in order to obtain scaffolds with a defined fiber structure and a suitable polymeric material needs to be chosen to provide good mechanical and chemical properties for the desired 3Dscaffold.

Here two polymers for electrospinning into 3D-fibrous scaffolds were compared. The first polymer was wellknown poly(lactic-co-glycolic acid) (PLGA), which has been widely studied (Kim et al., 2003; Katti et al., 2004; Bashur et al., 2006; Xin et al., 2007), and is FDA approved and used for many biomedical applications. The second polymer used was DegraPol ${ }^{\circledR}$ (DP), which was shown to meet essential requirements for 3D-medical scaffolds (Neuenschwander, 1994; Saad et al., 1997; Saad et al., 1999; Danielsson et al., 2006; Milleret et al., 2009). DP combines two important features, mechanical properties and rate of degradation in a way that they can be controlled independently from each other with minor chemical variations. Structurally, DP-polymers are block copolyester-urethanes containing two blocks: a rigid one that is crystallisable and an elastic block that is amorphous. Due to this structure, DP has improved elastomeric properties as compared to PLGA.

Scaffold architecture is defined particularly by the fiber diameter and their orientation, which have been shown to affect cellular behavior (Yasuda et al., 2004; Bashur et al., 2006; Baker and Mauck, 2007; Riboldi et al., 2008). Therefore, for direct comparison of the two polymers, it 
was important to produce scaffolds of similar fiber structure: particularly, the effects of applied voltage, flow rate, working distance and rotation velocity of the collecting mandrel on the fiber diameter and fiber orientation were studied. Later cell adhesion, cell orientation and proliferation on those fibers were compared.

Many medical scaffolds need to allow cell infiltration and tissue ingrowths. Therefore, scaffold porosity is a crucial parameter. Lack of pore interconnectivity of electrospun fiber scaffolds is a major drawback of the technique, since the scaffolds are very dense allowing only poor cell infiltration and tissue ingrowths. Recently, several solutions have been proposed; among those, cryoelectrospinning using ice-crystals as templates for enlarged pore formation leading to better cell infiltration in vitro and in vivo (Simonet et al., 2007; Leong et al., 2009). However, the technique has some limitations, as the controllability and homogeneity of the pore size are difficult to achieve (Simonet et al., 2007). Baker et al. proposed another way for producing scaffolds with controllable porosities based on mixed electrospinning between two polymers having different solubility (Kidoaki et al., 2005). The polymer to compose the scaffold is spun simultaneously with a water-soluble template polymer that can be removed by extensive rinsing after production of the scaffold. The removed co-spun polymer leaves behind voids throughout the scaffold thus providing improved porosity and interfiber spacing (Baker et al., 2008). Therefore the porosity of the final scaffold can be tuned by carefully selecting the water-soluble polymer (type and molecular weight), which deposits fibers with variable fiber diameters leading to increased pore sizes after its removal. In addition the ratio between water-soluble and water-nonsoluble polymer can be adjusted leading to variations in porosity and pore interconnectivity. Using this technique, PLGA and DP scaffolds were co-spun using different ratios of poly(ethylene glycol) as a water-soluble template polymer. Fiber diameter, alignment as well as mechanical properties and scaffold porosity was characterized. Cell adhesion, proliferation and infiltration-depth and -time into the scaffolds with different porosity were subsequently analyzed.

\section{Materials and Methods}

\section{Polymers}

Poly(lactic-co-glycolic acid) (Resomer ${ }^{\circledR}$, PLGA, Type RG 85:15, Mw = 280 kDa, Mat. Nr. 50897, Charge RES-0337) was purchased from Boehringer Ingelheim, Ingelheim, Germany. The polyester-urethane (trade name DegraPol ${ }^{\circledR}$ $(\mathrm{Mw}=70 \mathrm{kDa})$ was produced according to the procedure described by Lendlein et al., (1998) and Lendlein et al., (2001). Poly(ethylene glycol) (PEG, Mw=35 kDa) was obtained from Fluka (Germany). Chloroform (stabilized with ethanol) was obtained from Emanuele Centonze SA, Balerna (Chiasso), Switzerland.

\section{Scaffold production by electrospinning}

The electrospinning setup was assembled in-house and consisted of a syringe pump (Razel Scientific Instruments Inc., Georgia, VT, USA; http://www.rsclinical.com/ contact.htm), a spinning head consisting of a central stainless steel tube ( $1 \mathrm{~mm}$ inner diameter and $0.3 \mathrm{~mm}$ wall thickness, Angst \& Pfister AG, Zürich, Switzerland), a hollow cylindrical rotating aluminum mandrel for fiber collection (length: $100 \mathrm{~mm}$, diameter: $80 \mathrm{~mm}$, wall thickness: $5 \mathrm{~mm}$ ) and a DC high voltage supply (Glassman High Voltage Inc., High Bridge, NJ, USA). A coaxial jacket of chloroform saturated air prevented the needle exit from clogging by suppressing excessive solvent evaporation (Simonet et al., 2007).

Homogeneous polymeric solutions were prepared by letting the desired amount of polymer dissolve in chloroform at room temperature (RT) overnight. If not otherwise stated DP was used at $24 \mathrm{wt} \%$ and PLGA at 8 wt $\%$, both dissolved in ethanol-stabilized chloroform. The homogeneous solutions were loaded into a $2 \mathrm{~mL}$ syringe (B. Braun Melsungen AG, Germany) and pumped into the spinning heads. Electrospinning was optimized by varying the concentration of polymer in solution, the distance between the spinning head and the collecting mandrel (referred to as working distance), the flow rate, the velocity of the rotating mandrel and the applied voltage between the spinning head and the collector.

\section{Co-electrospinning}

For production of composite scaffolds, a second syringe head supplied by a second syringe pump was placed on the opposite side of the collector. One syringe head was used to spin the non-water soluble polymer (PLGA or DP), while the second syringe head was used to spin the watersoluble polymer (PEG) with variable flow rates for obtaining different composite fiber fleeces. Weight $\%$ of "non-water soluble" to weight\% of "water-soluble" between 100:0, 75:25, 50:50, 25:75 and 0:100 were produced.

\section{Scaffold characterization}

Fiber diameter was measured as described (Baker et al., 2006) mainly using light microscopy images: first a diagonal line was drawn from bottom left to top right of the image and the fiber diameter was measured, perpendicular to the fiber length, at the points where the line crossed the fiber. To measure the diameter, a linear measurement tool (http://rsbweb.nih.gov/ij/) after calibration with the scale bar of the microscope image was used. The diameters of the fibers were averaged over the field of view of all the images of a sample ( $\geq 20$ fiber diameters measured per sample). Analysis of scaffolds composed of fibers below $3 \mu \mathrm{m}$ in diameter was performed in an analogous way using scanning electron (SEM) micrographs.

Fiber orientation was assessed using light microscopy images. Firstly, the median orientation of the fibers towards the orientation of the scaffold was determined. Then, the angle between each fiber and the scaffold orientation (angle $\beta$ ) was measured using an Image J angle measurement tool. 
Fibers deviating less than $10^{\circ}$ from the scaffold orientation were considered as aligned and a score of 1 was assigned to them. A score of 0 was assigned to the fibers deviating more than $10^{\circ}$ from the scaffold orientation. The alignment score of the image (A) was calculated using the following formula:

$$
A=\left(\frac{\sum_{i=1}^{n} \text { scores }}{n}\right) \times 100[\%]
$$

where $n$ is the total number of fibers in the field of view. The alignment scores of different images of one condition were averaged and the mean values determined.

\section{Monitoring fiber composition and removal of PEG fibers}

Different composite fiber fleeces were produced as described above, adding 1:200 Vybrant DiD (Molecular Probes, Eugene, OR, USA) to the PLGA solution and 1:200 Vybrant DiI (Molecular Probes) to the PEG solution. Fluorescent images (Zeiss Axiovert 200M; Carl Zeiss, Oberkochen, Germany) were taken from the scaffolds asspun and after rinsing in water overnight at RT to remove the water-soluble polymer. The samples were subsequently dried over night in a vacuum oven at RT.

Determination of weight reduction and mesh density Fiber fleeces were weighed as-spun and after overnight rinse in water. The scaffolds were dried in a vacuum oven and the mass loss was determined. The bulk densities $\rho$ of the electrospun polymer meshes were determined gravimetrically using the weights of precisely cut mesh samples of defined area and thickness. The scaffold dimensions were measured using SEM micrographs of the scaffold. The overall mesh porosity $P$ was calculated according to the following equation:

$$
P=\left(1-\frac{\rho_{0}}{\rho}\right) \times 100[\%]
$$

$\rho_{0}=$ density of the polymer. The polymer density $\rho_{0}$ of PLGA and DP used to calculate were $1.26 \mathrm{~g} / \mathrm{cm}^{3}$ for PLGA and $1.15 \mathrm{~g} / \mathrm{cm}^{3}$ for DP, respectively (Simonet et al., 2007)

\section{Determination of mechanical properties}

The mechanical properties of polymer meshes were obtained from stress/strain curves measured at room temperature using a uniaxial load test machine (Instron tensile tester, High Wycombe, Buck, UK; model 5864) at a crosshead speed of $12.6 \mathrm{~mm} / \mathrm{min}$ using a sample gauge length of $12.6 \mathrm{~mm}(100 \% / \mathrm{min})$. Each sample was measured in triplicates.

\section{Culture of NIH-3T3 fibroblasts}

Mouse embryonic NIH-3T3 fibroblasts (ATCC, Teddington, Middlesex, UK; CRL-1658 ${ }^{\mathrm{TM}}$ ) were cultured in Dulbecco's Modified Eagle Medium (DMEM, ATCC No. SCRR-2010) supplemented with 10\% Newborn Calf Serum (Sigma-Aldrich, St. Louis, MO, USA, N4637) and 1\% Penicillin/Streptomycin (No. 15240-062, Gibco/BRL, Paisley, UK). The cells were maintained in T25 tissue culture polystyrene (TCPS) culture flasks (NUNC, Roskilde, Denmark) and incubated at $37{ }^{\circ} \mathrm{C}$ and $5 \% \mathrm{CO}_{2}$.
Table 1: Fiber diameters and orientation of the DPand PLGA-fibers prepared for cell adhesion and alignment studies.

\begin{tabular}{ccc}
\hline & Fiber Diameter & Alignment \\
\hline DP random & $3.5 \pm 1.5 \mu \mathrm{m}$ & - \\
DP aligned & $3.4 \pm 1.7 \mu \mathrm{m}$ & $89 \pm 11 \%$ \\
PLGA random & $4.96 \pm 0.9 \mu \mathrm{m}$ & - \\
PLGA aligned & $4.04 \pm 0.6 \mu \mathrm{m}$ & $95 \pm 5 \%$ \\
\hline
\end{tabular}

The medium was changed every other day. As cells proliferated well and no morphological changes with the passage number were observed, cells up to passage 20 were used.

\section{Cell alignment assay}

The number of Hoechst-stained nuclei was analyzed $2 \mathrm{~h}$, 1,3 and 7 days after seeding of 15,000 fibroblasts by fluorescence microscopy to determine cell proliferation (Zeiss Axiovert 200M, Germany). 3 random locations on every scaffold were selected and photographed $(20 \mathrm{x}$ magnification). After day 7, cells were fixed and imaged by laser scanning confocal microscopy (SP5, Leica Microsystems, Wetzlar, Germany) after staining for the actin cytoskeleton with Phalloidin-Alexa 488 (Invitrogen/ Molecular Probes) as described below. Cell orientation on aligned scaffolds was compared to cell orientation on random scaffolds. The experiment was carried in 5 replicates. Cell alignment was quantified where cells were considered as aligned if the angle between the longest cell axis and the scaffold's median orientation was smaller than $10^{\circ}$.

\section{Cell proliferation and infiltration into 3D-fiber fleeces}

For cell proliferation DP and PLGA fiber fleeces were used that have been produced with different ratios of coelectrospun PEG. The fleeces were cut into squares of about $5 \times 5 \mathrm{~mm}^{2}$ in size and were incubated in $500 \mu \mathrm{L} 20 \mu \mathrm{g} / \mathrm{mL}$ collagen type I (BD Biosciences, Heidelberg, Germany) in PBS solution for $2 \mathrm{~h}$, washed 3 times for $5 \mathrm{~min}$ in PBS and incubated in $1 \%$ penicillin/streptomycin in PBS solution overnight at RT. The fleeces were transferred into 24 well plates and 15,000 NIH-3T3 fibroblasts in $200 \mu \mathrm{L}$ medium were seeded onto the scaffolds for $2 \mathrm{~h}$. Subsequently fiber fleeces were transferred into a separate 24 well plate and $0.5 \mathrm{~mL}$ of tissue culture medium was added. The cells were cultivated for 1-28 days. In a separate 24 well plate 15,000 cells were plated and used as control cells. For infiltrations studies that were analyzed $1 \mathrm{~d}$ after seeding, a higher initial cell number of 1,000,000 cells / scaffold was used.

\section{AlamarBlue $^{\mathrm{TM}}$ proliferation assay \\ Cell proliferation was determined by alamarBlue ${ }^{\mathrm{TM}}$ assay (AbD SEROTEC, Düsseldorf, Germany; No BUF012A). The alamarBlue ${ }^{\mathrm{TM}}$ solution was diluted to $10 \%$ in the tissue culture medium and incubated for $4 \mathrm{~h}$ on NIH-3T3 fibroblasts. To avoid background signal of cells, which were not on the scaffolds, the fleeces were placed into}




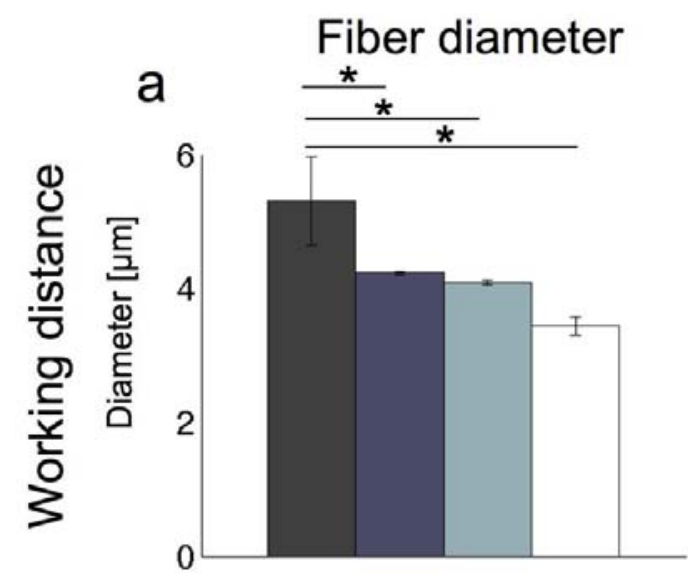

C

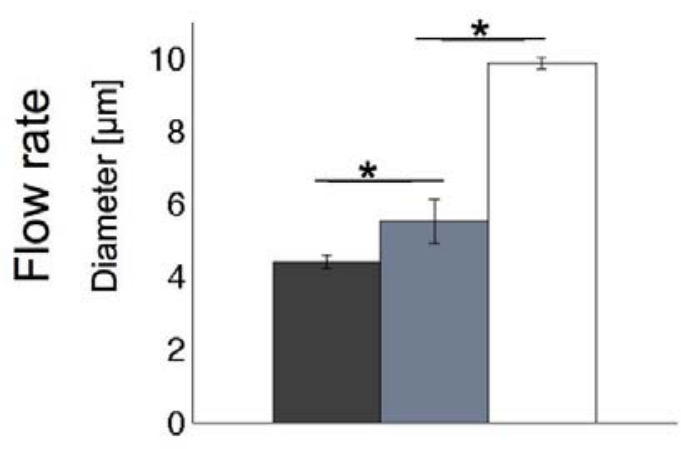

e

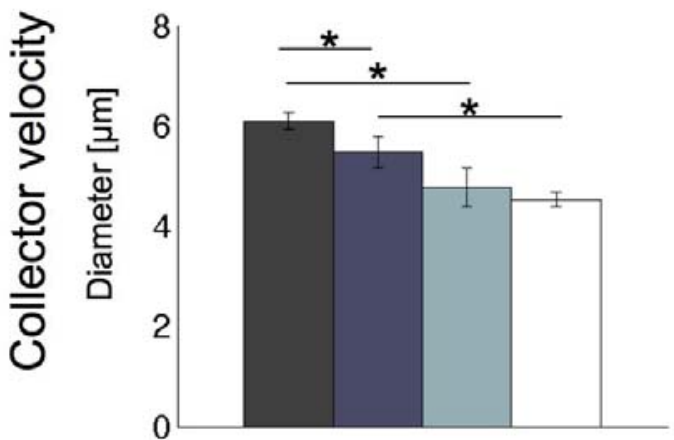

b

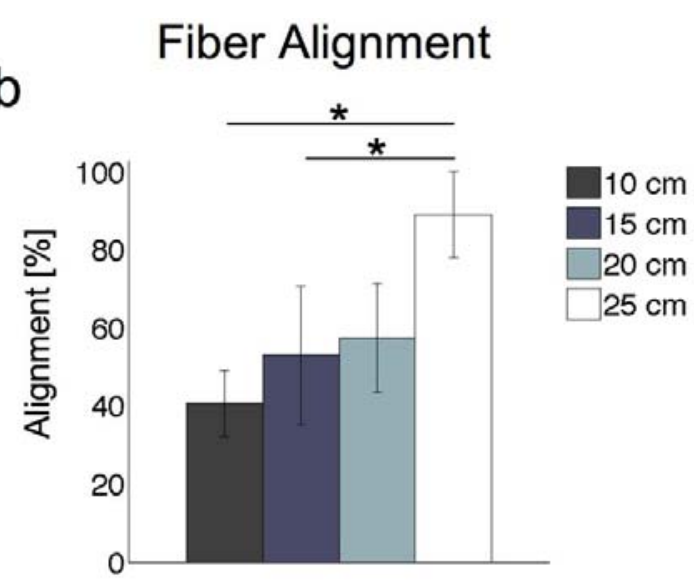

d

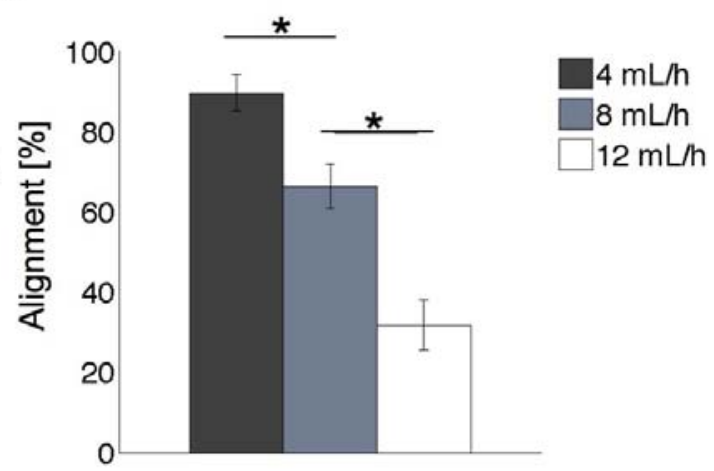

f
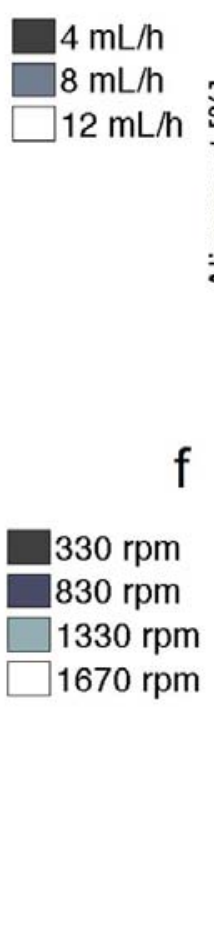

$12 \mathrm{~mL} / \mathrm{h}$
$10 \mathrm{~cm}$

$15 \mathrm{~cm}$

$20 \mathrm{~cm}$

$25 \mathrm{~cm}$

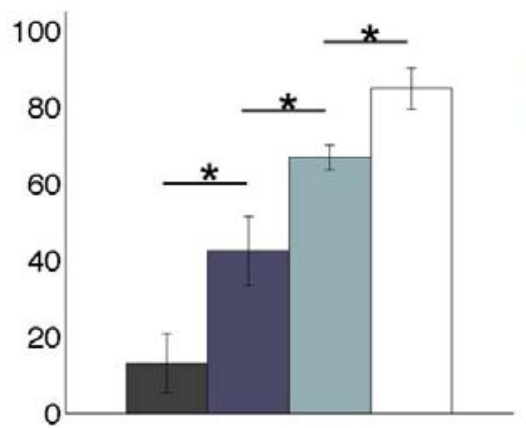

$330 \mathrm{rpm}$

$830 \mathrm{rpm}$

$1330 \mathrm{rpm}$

1670 rpm

Fig. 1. Correlations between electrospinning parameters and the resulting DP-fiber diameters and alignment, namely: the effect of the working distance on fiber diameter (a) and alignment (b); effect of the flow rate on fiber diameter (c) and alignment (d); and the effect of the mandrel velocity on the fiber diameter (e) and alignment (f). All the values represent mean values \pm standard deviations of at least 20 fibers on three samples. Asterisks indicate statistical significance $(p<0.05)$ between the two values under the respective line (after performing a 1-way ANOVA test).

fresh well plates before each measurement. After the incubation $400 \mu \mathrm{L}$ were collected and four times $100 \mu \mathrm{L}$ were placed into a 96 well plate. The fluorescence was determined by an Infinite M200, TECAN using exciting wavelength of $480 \mathrm{~nm}$ and emission wavelength of 530 nm. Four readings were performed per well. Cell proliferation was determined at day 0 ( $2 \mathrm{~h}$ after seeding the cells), and 4, 7, 10, 15, 21 and 28 days. The values represent mean values \pm standard deviation of at least 6 independent experiments; for the time points 21 and 28 days only 3 independent experiments were carried out.

\section{Assessment of cell infiltration into fiber fleeces}

At different time points ( 1 and 14 days) cell-seeded fiber fleeces were fixed with $4 \mathrm{w} / \mathrm{v} \%$ paraformaldehyde (PFA) dissolved in PIPES (65 mM), HEPES (25 mM), EGTA $(10 \mathrm{mM})$ and $\mathrm{MgCl}_{2}(3 \mathrm{mM})$, for $20 \mathrm{~min}$. Cells were permeabilized with $0.1 \%$ Triton X100 in PBS $(500 \mu \mathrm{L}$ per well) for $10 \mathrm{~min}$ and washed once with PBS. A staining solution composed of 1:2000 Hoechst 33342 (Invitrogen/ Molecular Probes) for staining the nuclei, and 1:200 Alexa488 Phalloidin (Invitrogen/Molecular Probes) for staining the actin cytoskeleton in $1 \mathrm{wt} \%$ solution of BSA (Bovine Serum Albumin, SAFC, Sigma-Aldrich) in PBS was incubated at RT for $2 \mathrm{~h}$. The wells were washed with PBS 3 times for $5 \mathrm{~min}$. Scaffolds were subsequently embedded in 'optimal cutting temperature compound' (OCT, TissueTek, Sakura Finetek Europe, Alphen a/d Rijn, the Netherlands). $8 \mu \mathrm{m}$ thick cross-sections were cut with a Cryostat (Microm HM560, MICROM International 
Fiber diameter

a
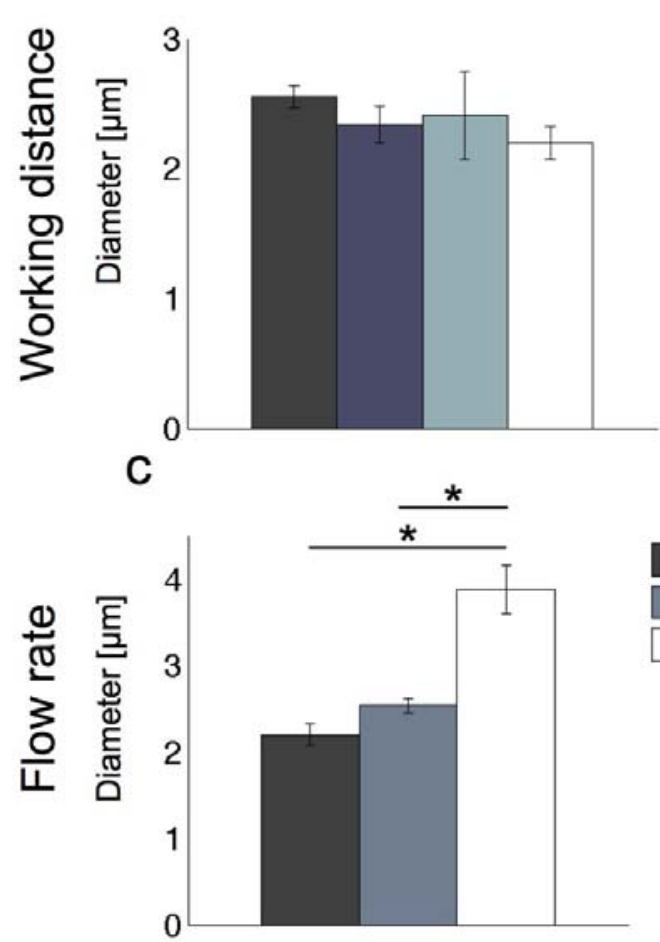

e

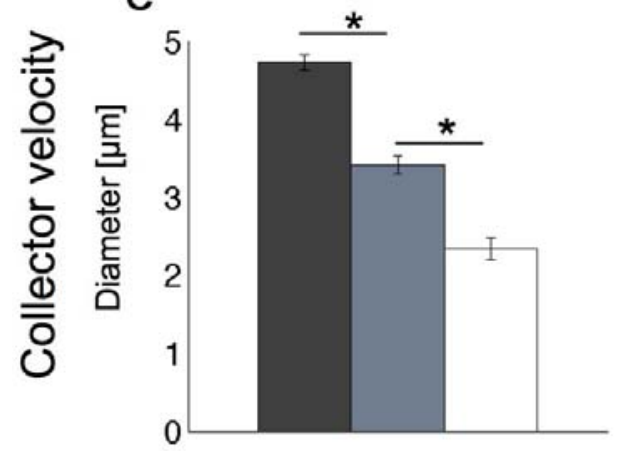

b

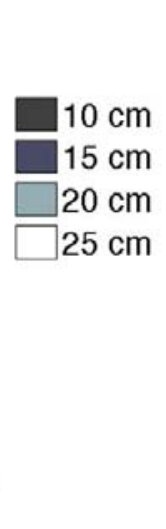

d

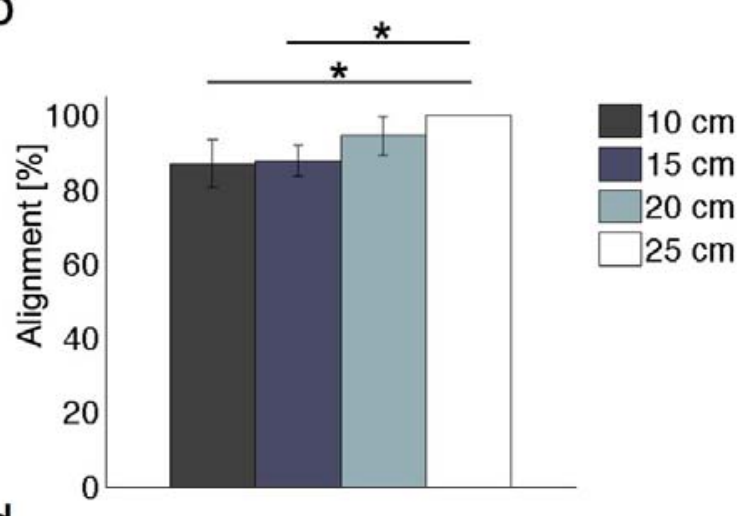

$4 \mathrm{~mL} / \mathrm{h}$

$8 \mathrm{~mL} / \mathrm{h}$

$12 \mathrm{~mL} / \mathrm{h}$

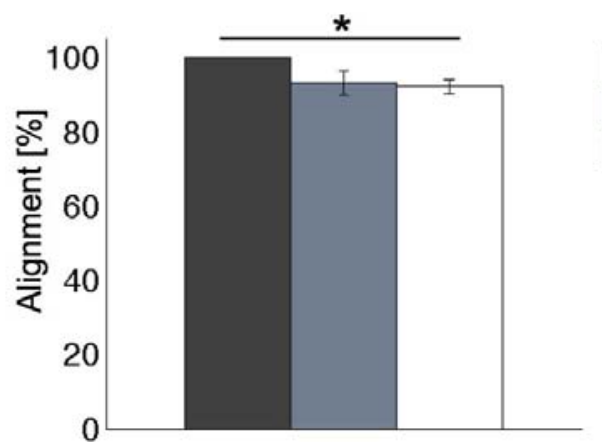

$4 \mathrm{~mL} / \mathrm{h}$

$8 \mathrm{~mL} / \mathrm{h}$

$12 \mathrm{~mL} / \mathrm{h}$

f

$17 \mathrm{rpm}$

$500 \mathrm{rpm}$

$1330 \mathrm{rpm}$
$17 \mathrm{rpm}$ $500 \mathrm{rpm}$ $1330 \mathrm{rpm}$

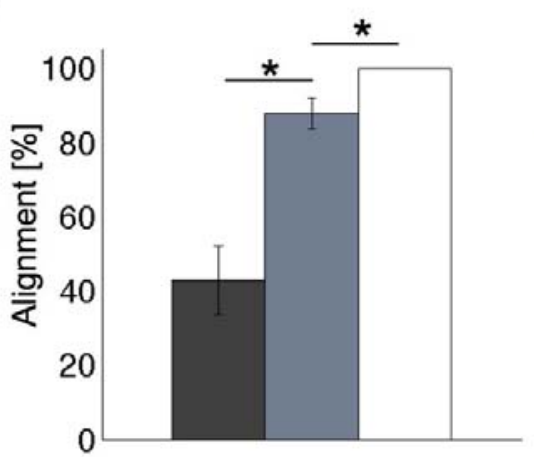

Fig. 2. Correlations between the electrospinning parameters and the resulting PLGA-fiber diameters and alignment. The effect of the working distance on the fiber diameter (a) and alignment (b); the effect of the flow rate on fiber diameter (c) and alignment (d); and the effect of the mandrel velocity on the fiber diameter (e) and alignment (f) was assessed. All the values represent mean values \pm standard deviations of at least 20 fibers on three samples. Asterisks indicate statistical significance $(p<0.05)$ between the two values under the respective line after performing a 1-way ANOVA test.

GmbH, Waldorf, Germany). Sections were then analyzed by fluorescence microscopy (Zeiss Axiovert 200M, Germany). A Matlab script was designed for quantifying cell penetration into the cross sections. In brief, scaffold boundaries were set manually for each image. A threshold was applied to fluorescence images, which were subsequently cleaned (noise removal) and segmented into regions corresponding to fluorescent cell signals. The centroid of every single region was calculated and defined as the centre of the cell. The distance between the cell centre and the closest scaffold boundary was then calculated and defined as the infiltration depth of the given cell. For a better comparison between different scaffolds, cell infiltration was calculated as a percentage of the section thickness. The values represent mean values \pm standard deviation of at least 3 scaffolds per time point.

\section{Scanning electron microscopy (SEM)}

Electrospun scaffolds were analyzed by SEM in order to obtain detailed information concerning the fiber morphology and interfiber spaces. Scaffolds for SEM analysis were produced by electrospinning of at least 30 min of spinning time and the resulting fleeces had a thickness between 200 and $500 \mu \mathrm{m}$. The scaffolds were vacuum dried overnight and sputter-coated with gold at $15 \mathrm{~mA}$ to obtain a $10 \mathrm{~nm}$ coating. Analysis was performed using a JEOL 6360LV scanning electron microscope (Tokyo, Japan). Micrographs were taken at magnifications between 100 and $1000 \mathrm{x}$ at accelerating voltage between 6-7 kV. 

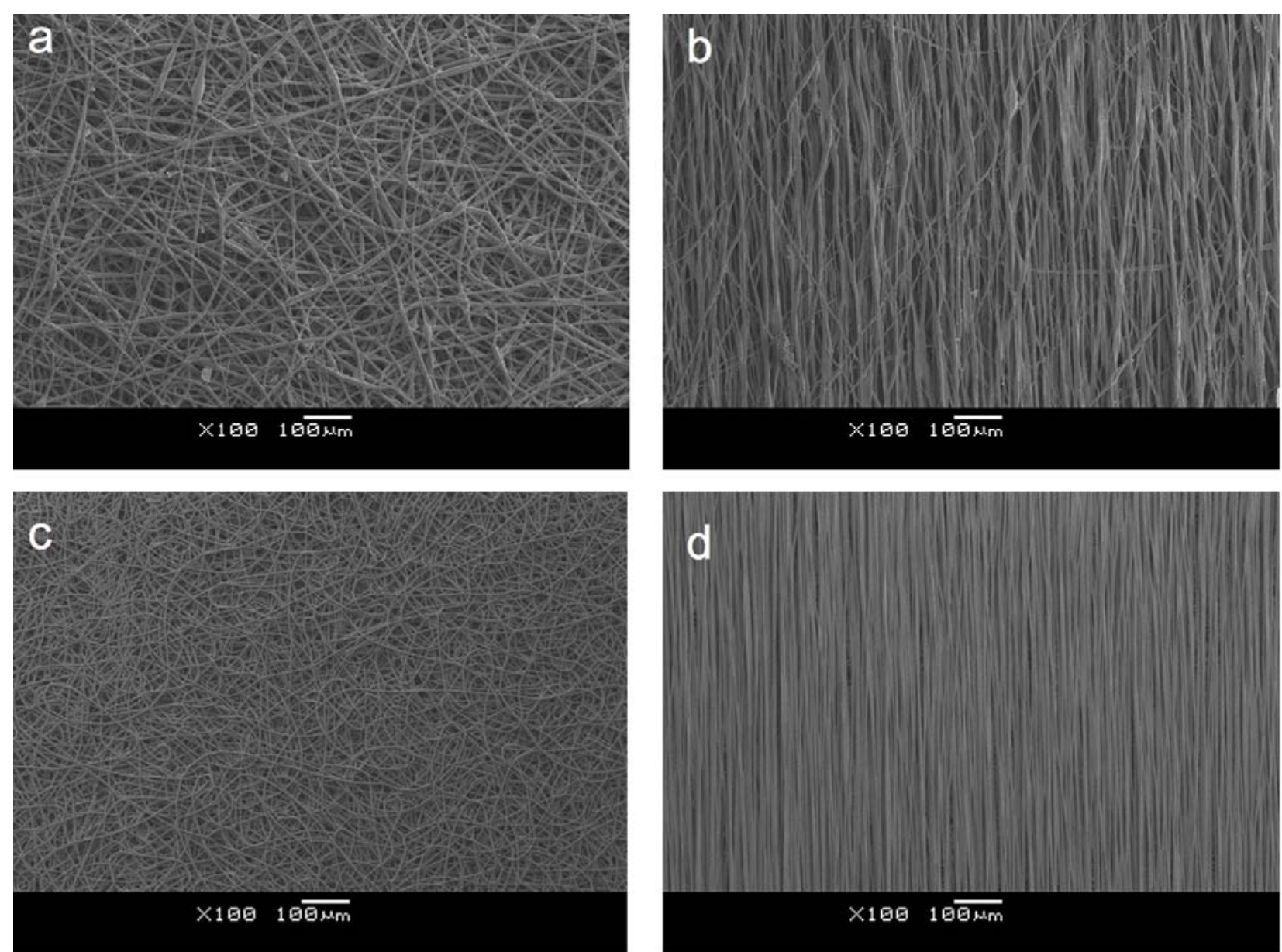

Fig. 3. Characterization of electrospun DP and PLGA-fibers by SEM imaging for tissue culture applications. Random (a, c) and aligned scaffolds (b, d) were produced with DP (23 wt \%, a-b) and PLGA (8wt $\%$, c-d) by varying the velocity of the rotating mandrel. The mandrel rotated $130 \mathrm{rpm}$ for random spinning and 1,330 rpm for aligned fibers.

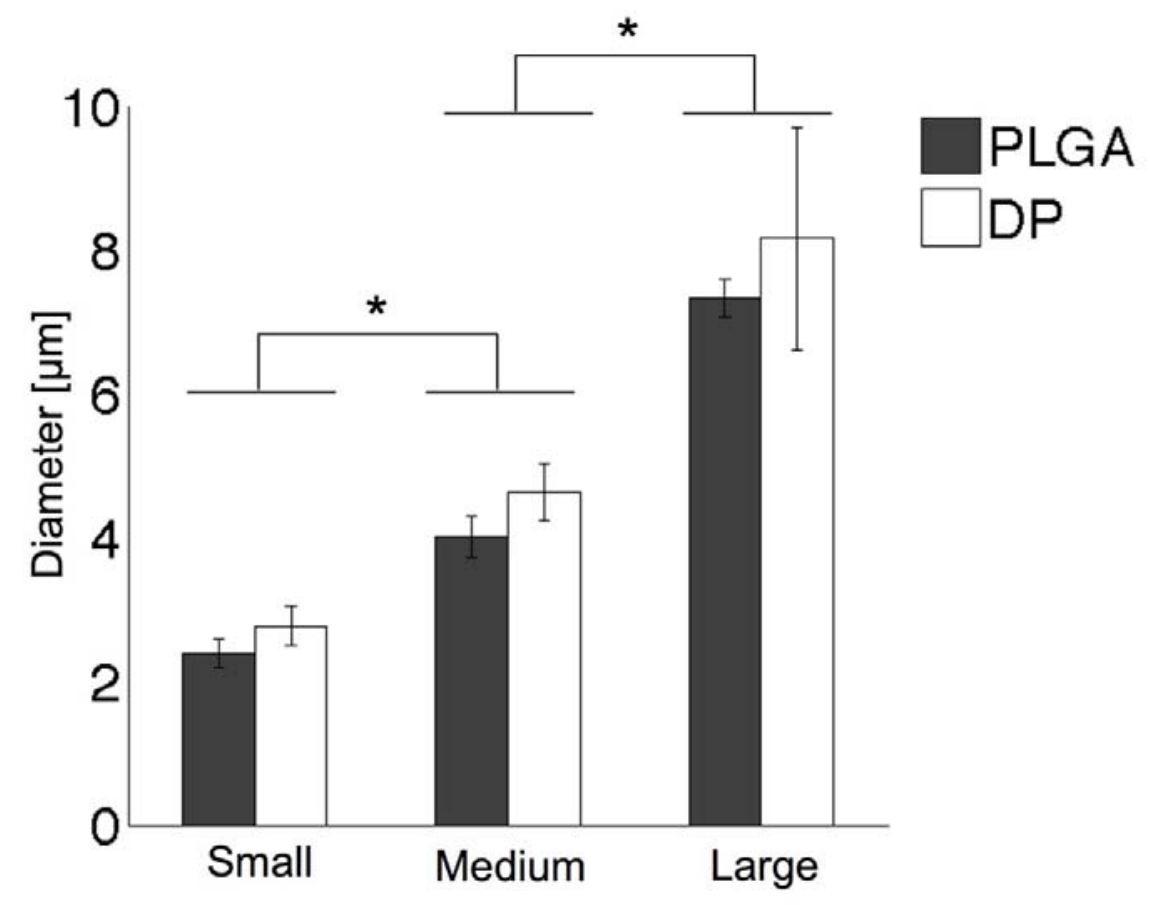

Fig. 4. Comparison of different fiber diameters of DP- and PLGA-fibers. The values represent mean values \pm standard deviations of 5 independent experiments. Performing a 2-way ANOVA test, the fiber diameter was found to be statistically different $(p<0.05)$ between the size groups ('small', 'medium' and 'large'), while no difference in diameter was found between DP and PLGA. 

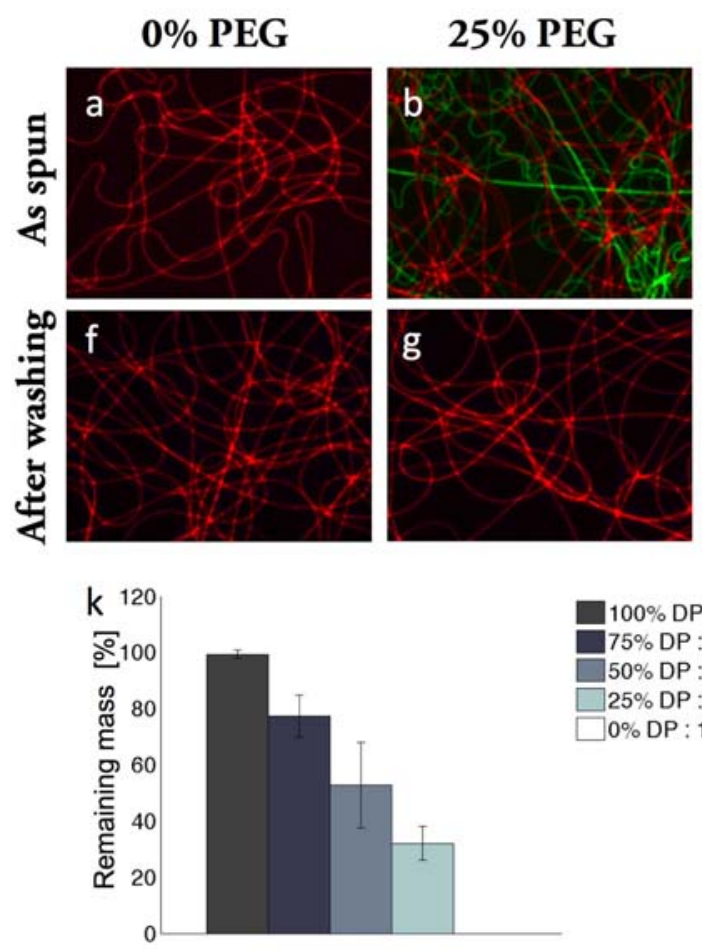

50\% PEG
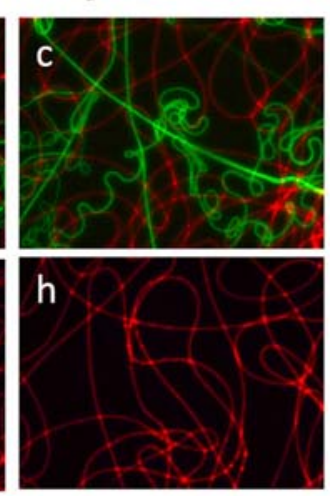

75\% PEG
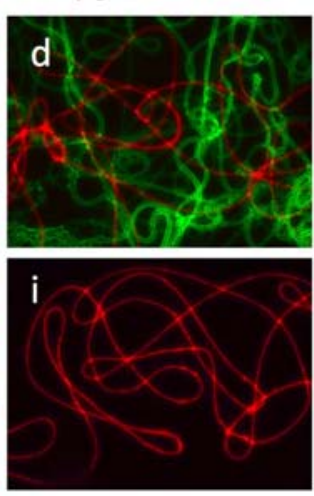

$100 \%$ PEG

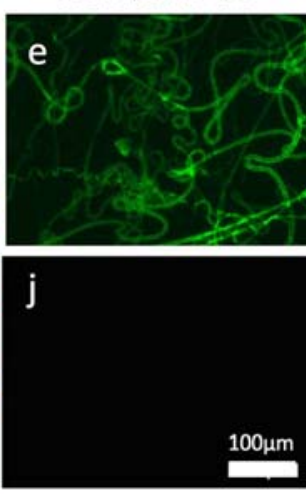

Fig. 5. 3D-fiber-fleeces with increased porosities can be produced with different ratios of water-insoluble and watersoluble polymers. a-j: fluorescence images of PLGA-scaffolds prepared with different PEG ratios: 0\% PEG (a, f); 25\% PEG (b, g); 50\% PEG (c, h); 75\% PEG (d, i) and 100\% PEG (e, j). PEG fibers were fluorescently labeled with Vybrant DiI (green) and PLGA fibers with Vybrant DiD (red). (a-e) shows images of the scaffolds as-spun and (f-j) after rinsing in water overnight. The remaining mass of DP-scaffolds produced with different ratios of PEG is shown in $\mathrm{k}$ and in 1 for PLGA-scaffolds. Each mean value \pm standard deviation represents the measurements made on 4 independent samples.

\section{Statistical analysis}

If not otherwise stated, the mean values were compared by one-way ANOVA analysis using Matlab 7.9 (the MathWorks Inc, Natick, MA, USA). Statistical significance was accepted for $p<0.05$ after comparing the mean values by Bonferroni test and was indicated with an asterisk within the graph.

\section{Results}

\section{Effects of electrospinning parameters on fiber morphology}

To produce 3D-scaffolds that mimique to a certain extent the fibrous structure of the native extracellular matrix, DegraPol $^{\circledR}$ (DP) and poly(lactid acid-co-glycolic acid) (PLGA) were electrospun under different conditions and fibers of defined morphologies were produced. The effects of some electrospinning parameters: namely the working distance, the flow rate and the collector velocity on the resulting DP-fiber diameter and orientation were demonstrated (Fig. 1). Increased working distance (from 10 to $25 \mathrm{~cm}$ ) led to a linear decrease in average fiber diameter being between $5.55 \mu \mathrm{m}$ at $10 \mathrm{~cm}$ down to 3.46 $\mu \mathrm{m}$ at $25 \mathrm{~cm}$ (Fig. 1a). DP-fiber diameter was found to increase with increasing flow rate (Fig. 1c), where an increase in flow rate from $4 \mathrm{~mL} / \mathrm{h}$ to $12 \mathrm{~mL} / \mathrm{h}$ led to fibers of $4.42 \mu \mathrm{m}$ and $9.81 \mu \mathrm{m}$ average diameter, respectively.
An increase in the collector velocity from 330 to 1670 rpm resulted in a decrease in average DP-fiber diameter from $6.08 \mu \mathrm{m}$ to $4.52 \mu \mathrm{m}$, respectively (Fig. 1e). Interestingly, fiber orientation was observed to follow inverse relations when varying these electrospinning parameters. The DP-fiber orientation increased from $41 \%$ for a working distance of $10 \mathrm{~cm}$ up to $89 \%$ at $25 \mathrm{~cm}$ (Fig. 1b). Additionally, DP-fiber orientation decreased from $89 \%$ to $32 \%$ when increasing the flow rate from $4 \mathrm{~mL} / \mathrm{h}$ to 12 $\mathrm{mL} / \mathrm{h}$ (Fig. 1d). Finally, as shown in Fig. 1f, DP-fibers deposited in a more aligned manner when the mandrel velocity was increased (13\% at $330 \mathrm{rpm}$ compared to $85 \%$ at 1,670 rpm). Similar results were obtained for PLGA fibers (see Fig. 2). SEM images of aligned and random fibers produced from DP and PLGA are found in Fig. 3.

The optimized electrospinning conditions allowed production of DP- and PLGA-fibers with defined diameters between 2 and $8 \mu \mathrm{m}$ (Fig. 4). The smallest fiber diameters were found to be $2.4 \mu \mathrm{m} \pm 0.2 \mu \mathrm{m}$ for PLGA and $2.8 \mu \mathrm{m}$ $\pm 0.3 \mu \mathrm{m}$ for DP), the medium fiber diameters were 4.0 $\mu \mathrm{m} \pm 0.3 \mu \mathrm{m}$ for PLGA and $4.6 \mu \mathrm{m} \pm 0.4 \mu \mathrm{m}$ for DP), and $7.3 \mu \mathrm{m} \pm 1.4 \mu \mathrm{m}$ for PLGA and $8.1 \mu \mathrm{m} \pm 1.6 \mu \mathrm{m}$ for DP for the largest fiber diameters.

\section{Characterization of fibrous scaffolds with increased porosity}

DP- and PLGA fibrous scaffolds were produced by cospinning with different ratios of PEG $(0,25,50,75,100 \%$, 

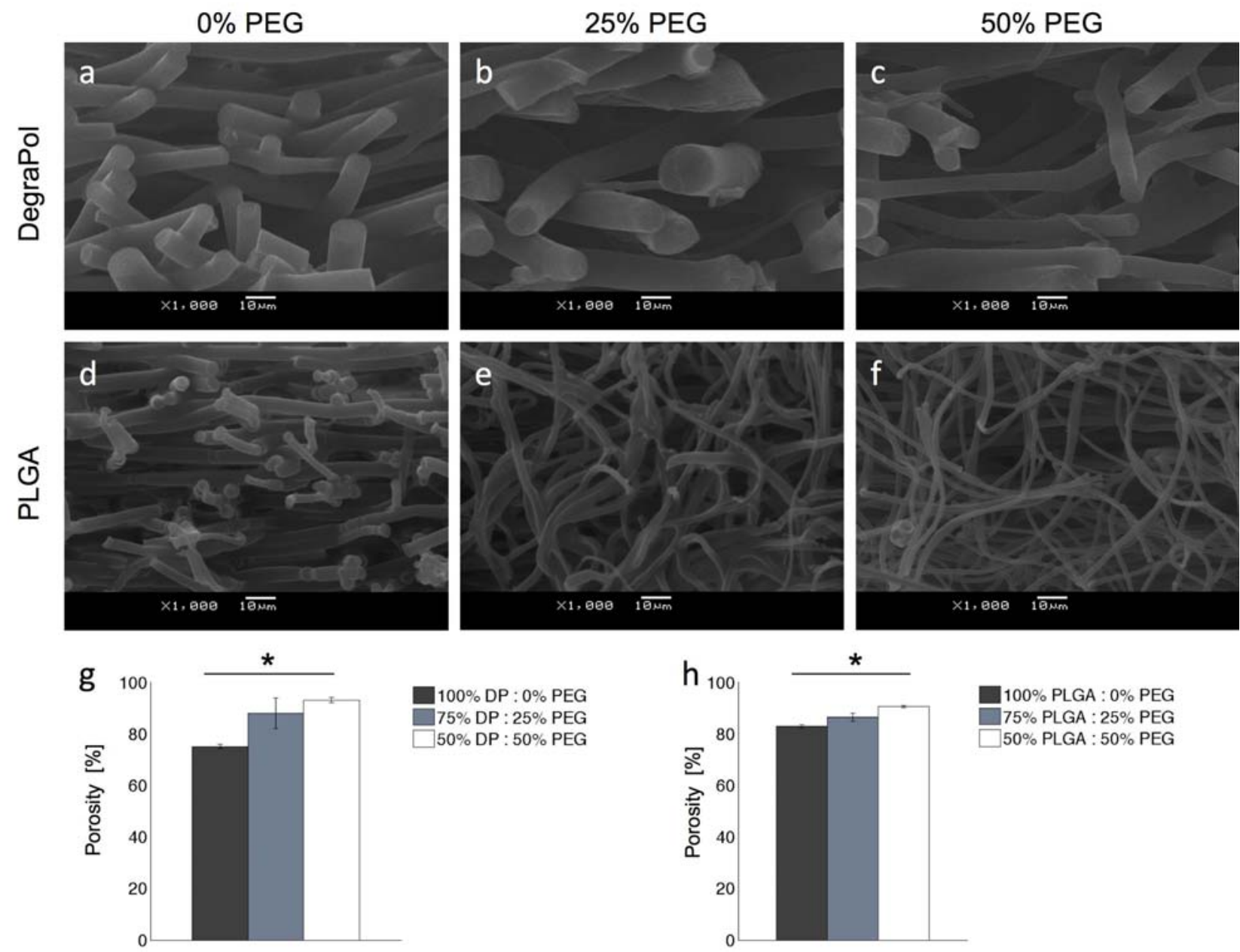

Fig. 6. SEM micrographs of cross sections of DP- (a-c) and PLGA-3D-fiber scaffolds (d-f) prepared with increasing ratios of PEG: $0 \%(\mathbf{a}, \mathbf{d}), 25 \%(\mathbf{b}, \mathbf{e})$ and $50 \%(\mathbf{c}, \mathbf{f})$. Porosity was calculated with equation (2) for DP-scaffolds (g) and PLGA-scaffolds (h). The porosities are mean values \pm standard deviations of 4 independent samples per condition. The values below the lines are statistically different from each other $(p<0.05)$ as determined by 1 -way ANOVA.

Fig.5). Fluorescent images of co-spun scaffolds in which PEG fibers were stained with Vybrant DiO (green) and PLGA fibers were stained with Vybrant DiD (red) were produced as spun, (Fig. 3a-e) and after removal of the water-soluble polymer (Fig. 5f-j). The PEG fibers were entirely removed in water, as no residual green signal was detected after washing. Similar results were found for DPscaffolds (not shown). In addition scaffolds of the same composition were produced and the mass loss, due to PEG removal was determined (Fig. 5k). It resulted in losses in mass for DP scaffolds of $0.6 \pm 1.4 \%$ for scaffolds produced with $0 \%$ PEG, $22.5 \pm 7.5 \%$ for scaffolds produced with 25 $\%$ PEG, $47.2 \pm 15.3 \%$ for scaffolds produced with $50 \%$ PEG, $68.2 \pm 6.1 \%$ for scaffolds produced with $75 \%$ PEG and scaffolds containing $100 \%$ PEG were completely removed. Similarly, PLGA-scaffolds produced with 0, 25, 50,75 and $100 \%$ PEG were found to have mass losses of $0.5 \pm 1.8 \%, 24.2 \pm 3.5 \%, 51.8 \pm 4.6 \%, 78,0 \pm 5.8 \%$ and $100 \%$, respectively (Fig. 51). Cross-sections of scaffolds produced with 0,25 and 50\% PEG were analyzed by SEM after removal of PEG (Fig. 6a-c for DP and Fig 6d-f for PLGA-scaffolds). The interfiber distances were observed to be larger when scaffolds were produced with increased
PEG ratios. Scaffolds produced with higher amounts than $50 \%$ PEG were not stable and thus were not used for cross sectional analysis or for cell experiments. The SEM micrographs were also used to measure the thickness of the scaffolds. DP scaffolds produced with $0 \%, 25 \%$ and $50 \%$ PEG had a thickness of $496 \pm 19 \mu \mathrm{m}, 387 \pm 15 \mu \mathrm{m}$ and $416 \pm 43 \mu \mathrm{m}$; while PLGA scaffolds produced with 0 , 25 and $50 \%$ PEG were $253 \pm 56 \mu \mathrm{m}, 350 \pm 52 \mu \mathrm{m}$ and 421 $\pm 59 \mu \mathrm{m}$ thick, respectively. The scaffold porosity was shown to increase with increasing PEG ratios: from 75.2 $\pm 0.7 \%$ for DP produced with $0 \%$ PEG, to $88.1 \pm 6.0 \%$ and $93.2 \pm 0.9 \%$ for DP produced with $25 \%$ and $50 \%$ PEG, respectively (Fig. $6 \mathrm{~g}$ ). In the case of PLGA scaffolds, the porosity varied from $83.0 \pm 0.6 \%$ (when produced without PEG) to $86.5 \pm 1.5 \%$ (produced with $25 \%$ PEG) and 90.7 $\pm 0.4 \%$ (produced with $50 \%$ PEG) (Fig. $6 \mathrm{~h}$ ). The experiments indicate that the porosity of the scaffolds after removal of PEG increased with the amount of watersoluble polymer used during production independently of the chemistry of the non-water soluble polymer. These findings indicate that the porosity can be tuned by selecting the ratio of soluble polymer to be co-spun as a space holder. 
a

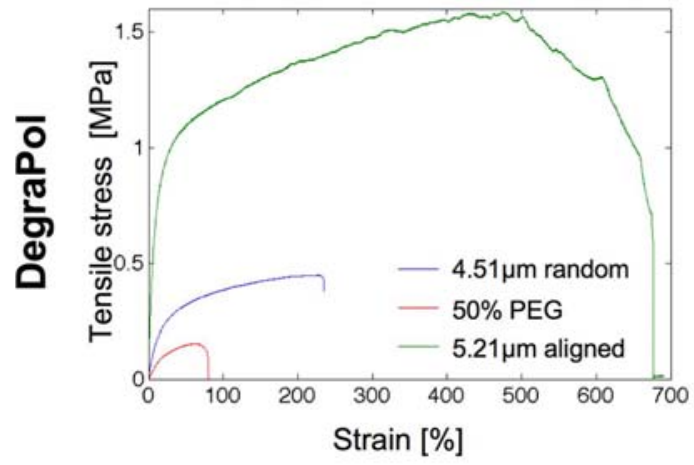

C

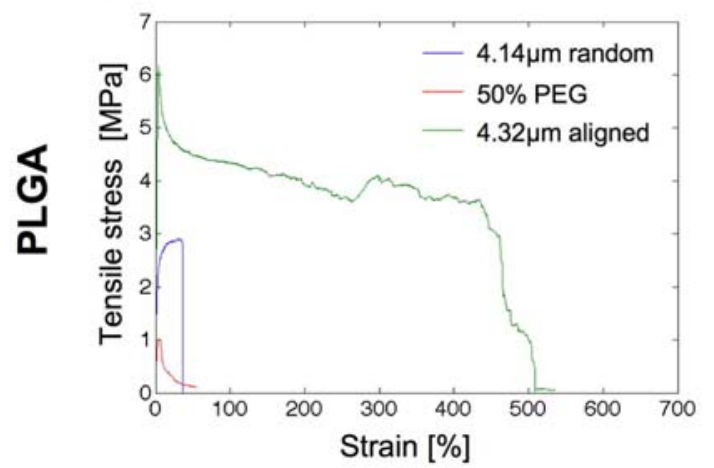

b

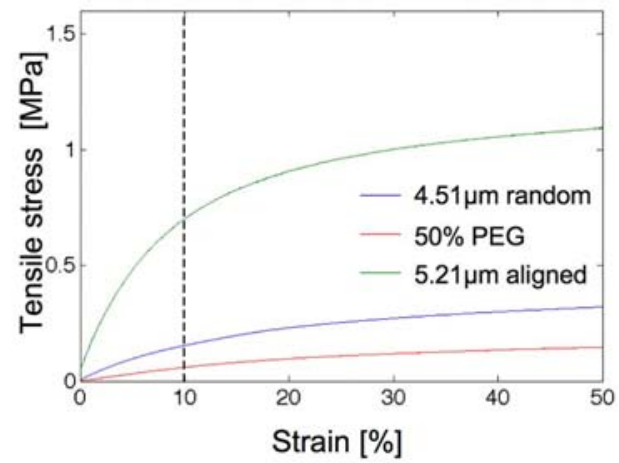

d

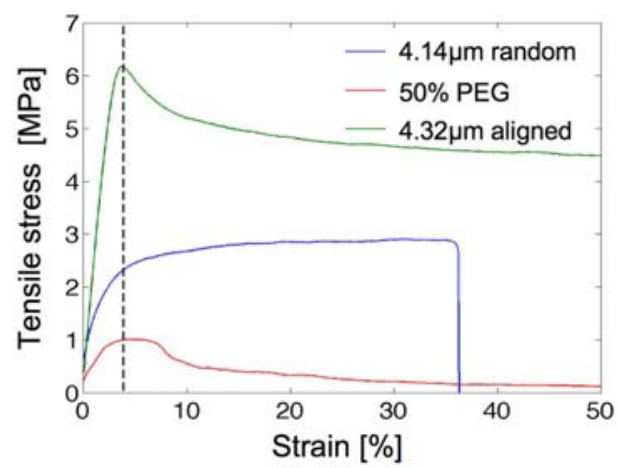

Fig. 7 Stress-strain curves for representative DP (a and $\mathbf{b})$ and PLGA scaffolds (c and $\mathbf{d})$. $\mathbf{a}$ and $\mathbf{b}$ show the strain on the scaffolds until breakage, while $\mathbf{b}$ and $\mathbf{d}$ are limited to a strain of $50 \%$ for better visualization of the elastic regime.

\section{Effect of fiber diameter and orientation on the mechanical properties}

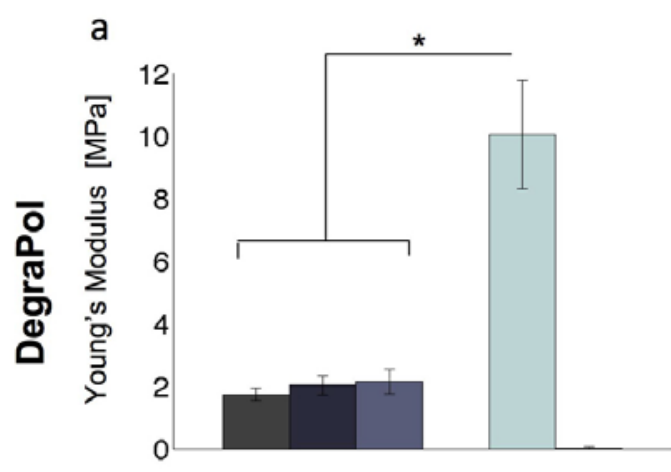

b

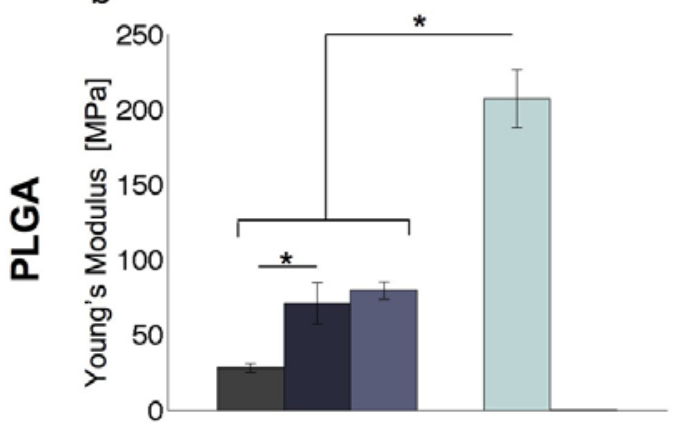

\section{Effect of the porosity on the mechanical properties}

C
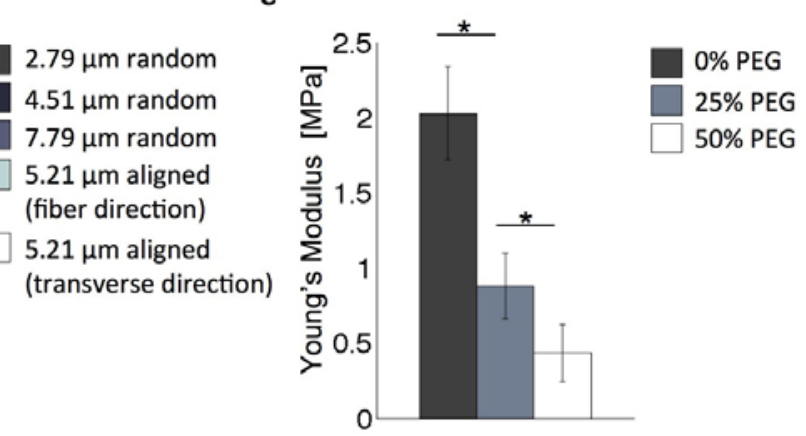

d

$2.06 \mu \mathrm{m}$ random

$4.14 \mu \mathrm{m}$ random

$6.56 \mu \mathrm{m}$ random

$4.32 \mu \mathrm{m}$ aligned (fiber direction)

$4.32 \mu \mathrm{m}$ aligned (transverse direction)

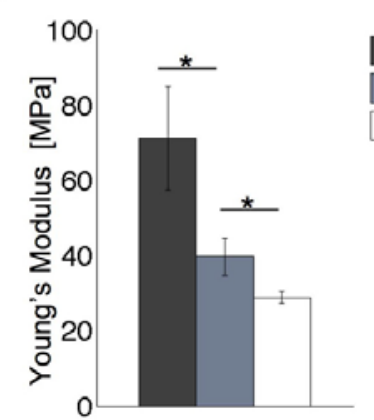

O\% PEG

$25 \%$ PEG

$50 \%$ PEG

Fig. 8. Influence of scaffold morphology on the Young's modulus. The effect of the fiber diameter and orientation affects on the Young's modulus was assessed for DP (a) and PLGA (c). The influence of increased porosity of DP (b) and PLGA (d) scaffolds led to decreased Young's moduli. The values below the lines are statistically different from each other $(p<0.05)$ as determined by 1-way ANOVA. Young's moduli were obtained from stress strain curves, examples of stress-strain curves are shown in Fig. 7. 


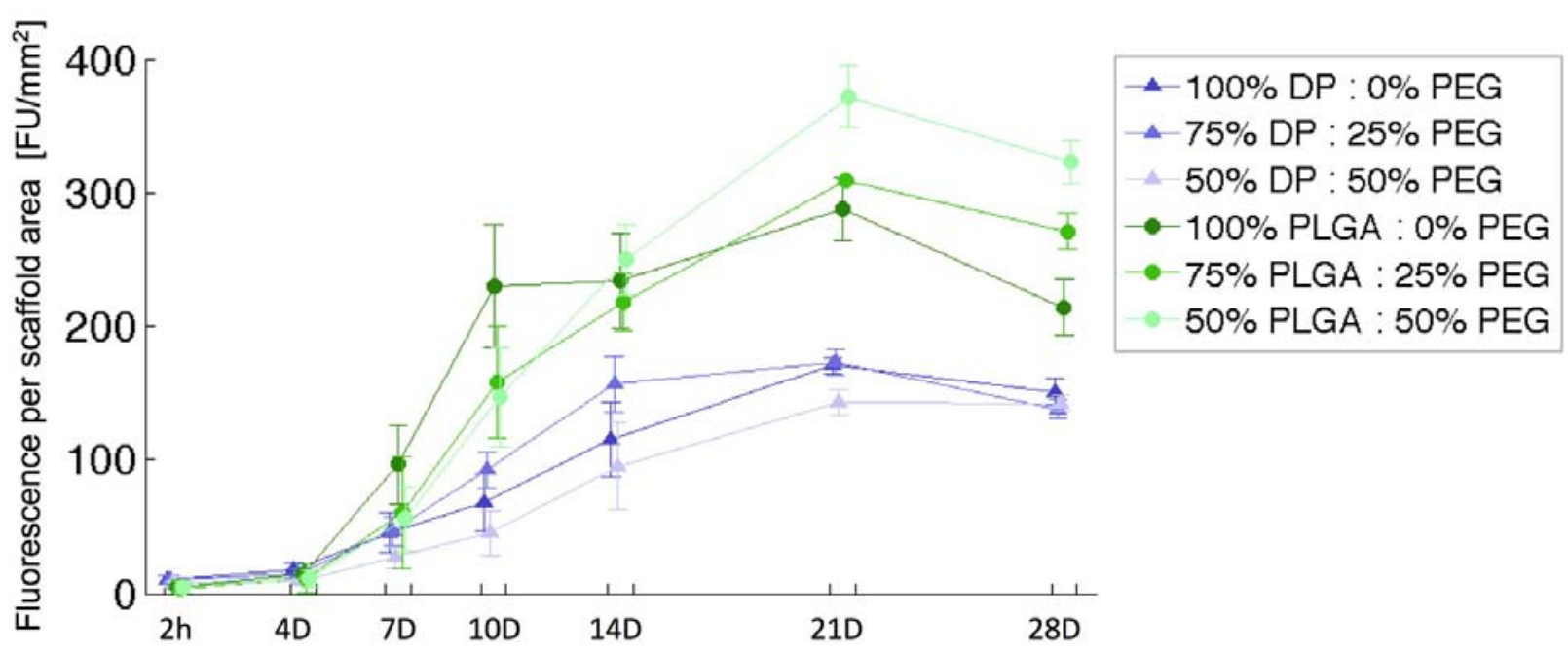

Fig. 9. NIH-3T3 fibroblasts proliferate on DP- and PLGA-3D-fiber-scaffolds. Scaffolds were produced by cospinning between DP and PLGA and variable ratios of PEG ( $0 \%, 25 \%$ and $50 \%$, respectively). PEG was removed by extensive rinsing prior to seeding the cells. 15,000 NIH-3T3 fibroblasts were placed on the fleeces and cell proliferation was determined after $2 \mathrm{~h}$, and 4, 7, 10, 14, 21 and 28 days. An increase in cell proliferation was observed on all scaffolds, however higher proliferation was observed on PLGA scaffolds compared to DP scaffolds. No difference of the porosity on cell proliferation could be observed.

\section{Mechanical properties of selected scaffolds}

Stress strain curves were measured for DP and PLGA scaffolds with various morphologies ( $7 \mathrm{a}$ and c). Mechanical properties, specially the Young's modulus of the scaffolds could be derived from these curves (Tables 2 and 3). The Young's modulus of fibrous meshes was significantly different between DegraPol and PLGA scaffolds. Randomly oriented DP-scaffolds had a Young's modulus of about $2 \mathrm{MPa}$, while random PLGA-scaffolds were found to be much stiffer (63 $\mathrm{MPa}$ in average). Interestingly, the Young's Modulus seems to increase slightly with the fiber diameter for PLGA: the Young's modulus of $28.11 \pm 2.89,71.13 \pm 13.78$ and $79.54 \pm 5.86$ MPa were obtained for scaffolds composed of fibers of 2.06, 4.14 and $6.56 \mu \mathrm{m}$ in diameter (Fig. 8c). Orientation of the fibers dramatically affected the mechanical properties as scaffolds with aligned fibers had a much higher Young's modulus (in the direction of the fibers) and lower in the transverse direction, compared to randomly oriented scaffolds $(10.04 \pm 1.73$ in the fiber direction and $0.04 \pm 0.03 \mathrm{MPa}$ in transverse direction versus $2.03 \pm 0.31 \mathrm{MPa}$ for random scaffolds for $\mathrm{DP}$; and $207.17 \pm 19.23$ in the fiber direction and $0.07 \pm 0.02 \mathrm{MPa}$ in transverse direction versus $71.13 \pm 13.78 \mathrm{MPa}$ for random scaffolds for PLGA). Another parameter affecting the scaffold's mechanical properties is porosity. Scaffolds with increased porosity were found to have reduced Young's Moduli (Fig. 8c and d). When DegraPol scaffolds were produced with $25 \%$ and $50 \%$ of PEG a Young's modulus of only $43 \%$ and $22 \%$ of the $100 \%$ DP scaffold were determined, while PLGA scaffolds produced with $25 \%$ and $50 \%$ PEG had a modulus of $56 \%$ and $41 \%$ of a $100 \%$ PLGA scaffold. Yield elongation was not found to be statistically (1-way ANOVA) different among DP samples (7.6-10.2\%, Table 2) or PLGA samples (3.8-4.3\%,
Table 3), but differed between DP and PLGA. Additionally, tensile strength and elongation at break were found to follow the same trends as the Young's Moduli when scaffold characteristics were modified (Fig. 7a and c).

\section{Cell proliferation and infiltration into 3D-fiber- fleeces with increased porosity}

These experiments were performed to study the effect of different scaffold porosities (produced with 0, 25 and 50\% water-soluble polymer) on cell attachment and cell infiltration into the scaffolds with time. Fig. 9 shows that cells proliferated on all scaffolds however cells proliferated faster on PLGA-scaffolds compared to DP-scaffolds. Different porosities of DP- and PLGA-scaffolds did not seem to have an effect on cell proliferation. Similar findings were already observed on scaffolds produced with different fiber alignment (Fig. 10a), where cells proliferated faster on PLGA compared to DP scaffolds independently on the scaffold alignment. For both scaffolds cells oriented along the fiber axis (Fig. 10b and c-j).

To analyze the cell infiltration depth into the $3 \mathrm{D}$ scaffolds produced with different porosities, NIH-3T3-cells were cultured for 2 weeks on DP- and PLGA-fiber-fleeces and subsequently fixed and stained with Alexa-488 Phalloidin. Cryosections of scaffolds were made and the penetration depth was analyzed (Fig. 11a-f). Cells were found to be most homogeneously distributed within scaffolds with highest porosity (DP with 50\% PEG in Fig. 11c and PLGA with 50\% PEG in Fig. 11f) compared to scaffolds produced with $25 \%$ PEG (DP, Fig. 11 and PLGA, Fig. 11e), while cells cultivated in scaffolds produced without water-soluble polymer were mostly present at the surfaces of the scaffolds (Fig. 11 and 11d, respectively). Cell penetration depth was then measured and related to the scaffold thickness where $100 \%$ cell penetration was 

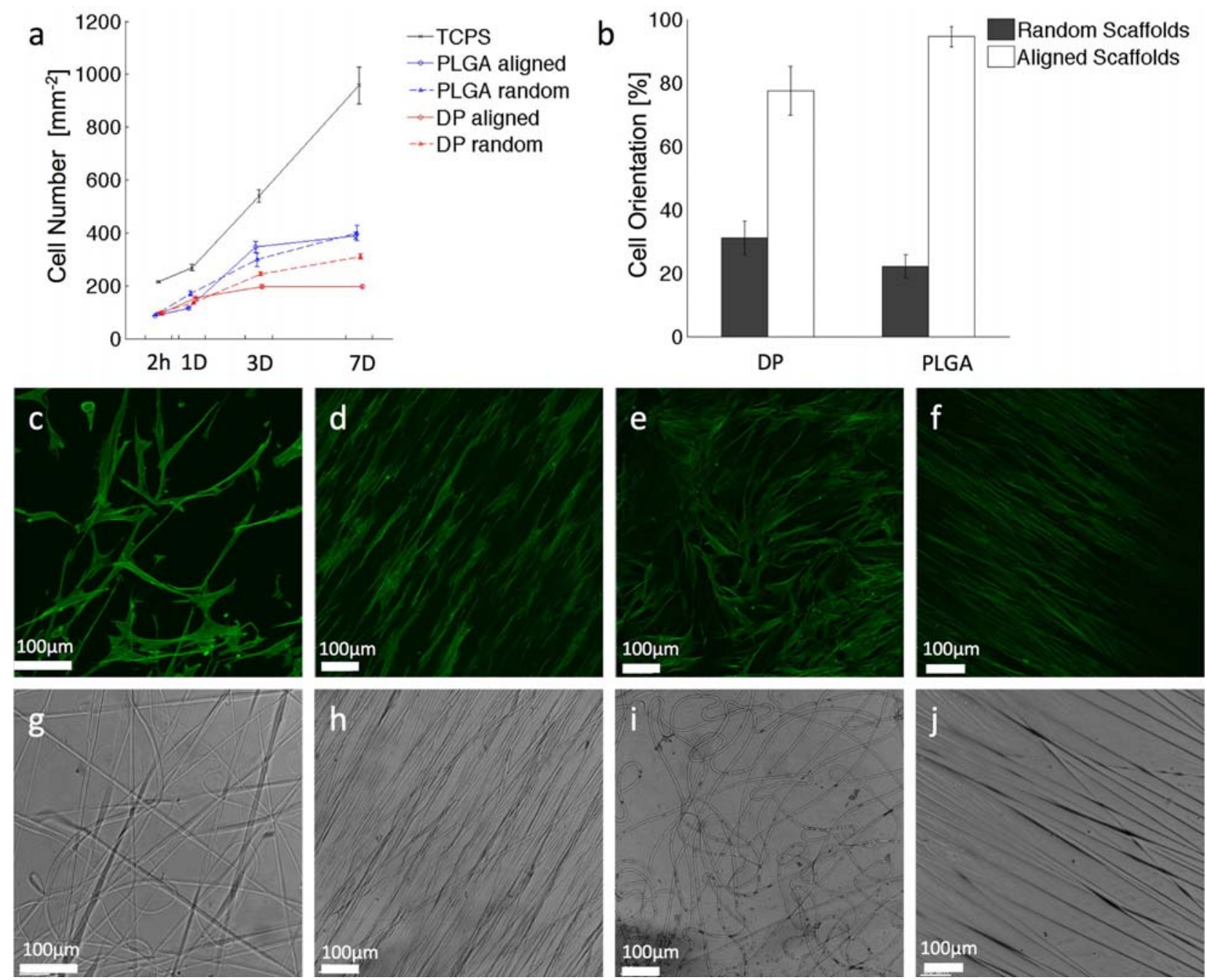

Fig. 10. Cell proliferation and alignment on DP- and PLGA- fibers. NIH-3T3 fibroblasts were cultivated during six days on random and on aligned DP- and PLGA-fibers (a). Tissue culture polystyrene (TCPS) was used as control. The number of cell nuclei was assessed microscopically after $2 \mathrm{~h}, 1,3$ and $7 \mathrm{~d}$. Normalized numbers of cell nuclei \pm standard deviations are presented from 3 images per scaffold in 5 replicates. Cell alignment on DP- and PLGA-fibers is presented as percentages of aligned cells (b). Each mean value \pm standard deviations represents aligned cells of 3 images ( $>15$ cells per image).

Cell alignment on DP- and PLGA-scaffolds: NIH 3 T3 fibroblasts were cultivated on DP (c, d, g, h) and on PLGA $(\mathbf{e}, \mathbf{f}, \mathbf{i}, \mathbf{j})$ fibers. The fibers are randomly oriented in $\mathbf{c}, \mathbf{e}, \mathbf{g}$ and $\mathbf{i}$ whereas aligned in $\mathbf{d}, \mathbf{f}, \mathbf{h}$ and $\mathbf{j}$. Random DP scaffolds had a diameter of $4.52 \pm 1.3 \mu \mathrm{m}$, random PLGA fibers of $4.34 \pm 0.5 \mu \mathrm{m}$ while aligned fibers of DP had a diameter of $4.02 \pm 1.1 \mu \mathrm{m}$ with an alignment score of $85 \%$ and aligned PLGA fibers a diameter of $3.6 \pm 0.8 \mu \mathrm{m}$ and an alignment score of $98 \%$. After $7 \mathrm{~d}$ the samples were fixed and the actin skeleton was stained with Alexa-488 Phalloidin (green signal, c-f). The results showed that fibroblasts were able to align along the direction of the fibers. The orientation of the fibers is visible in the bright field images $\mathbf{g}-\mathbf{j}$.

defined for a cell reaching the middle of the scaffold. The cells were then classified according to their infiltration depth in 4 different groups $(0-25 \%, 25-50 \%, 50-75 \%$ and $75-100 \%$ infiltration, Fig. 11g). $62 \pm 4 \%$ of the cells were found in the periphery of the scaffold for DP-fleeces prepared without $\mathrm{PEG}$, and only $7 \pm 1 \%$ reached the middle of the scaffold (75-100\% infiltration); cell infiltration was much more homogeneous on DP-fleeces prepared with $50 \%$ PEG, where $38 \pm 0.4 \%, 24 \pm 2 \%, 21 \pm 0.5 \%$ and 17 $\pm 2 \%$ of the cells infiltrated into $0-25 \%, 25-50 \%, 50-75 \%$ and $75-100 \%$ of the scaffold thickness. Infiltration studies on PLGA scaffolds (Fig. 11h) revealed very similar trends. The numbers of cells located at $0-25 \%, 25-50 \%, 50-75 \%$,
$75-100 \%$ of the thickness of the scaffold were found to be $61 \pm 7 \%, 19 \pm 3 \%, 12 \pm 5 \%$ and $8 \pm 1 \%$ for PLGA produced without PEG, and $39 \pm 3 \%, 25 \pm 2 \%, 20 \pm 3 \%$ and $16 \pm 2 \%$ for PLGA produced with 50\% water-soluble polymer. For both polymers scaffolds produced with $25 \%$ PEG produced intermediate values for cell infiltration were found. Summarizing one could say that increased porosity of the scaffolds led to strong enhancement of cell infiltration independently of the polymer scaffold used.

The scaffolds produced with increased porosities were further analyzed for the way of cell infiltration: as cell infiltration could either result from more efficient cell seeding into larger pore scaffolds or be due to enhanced 

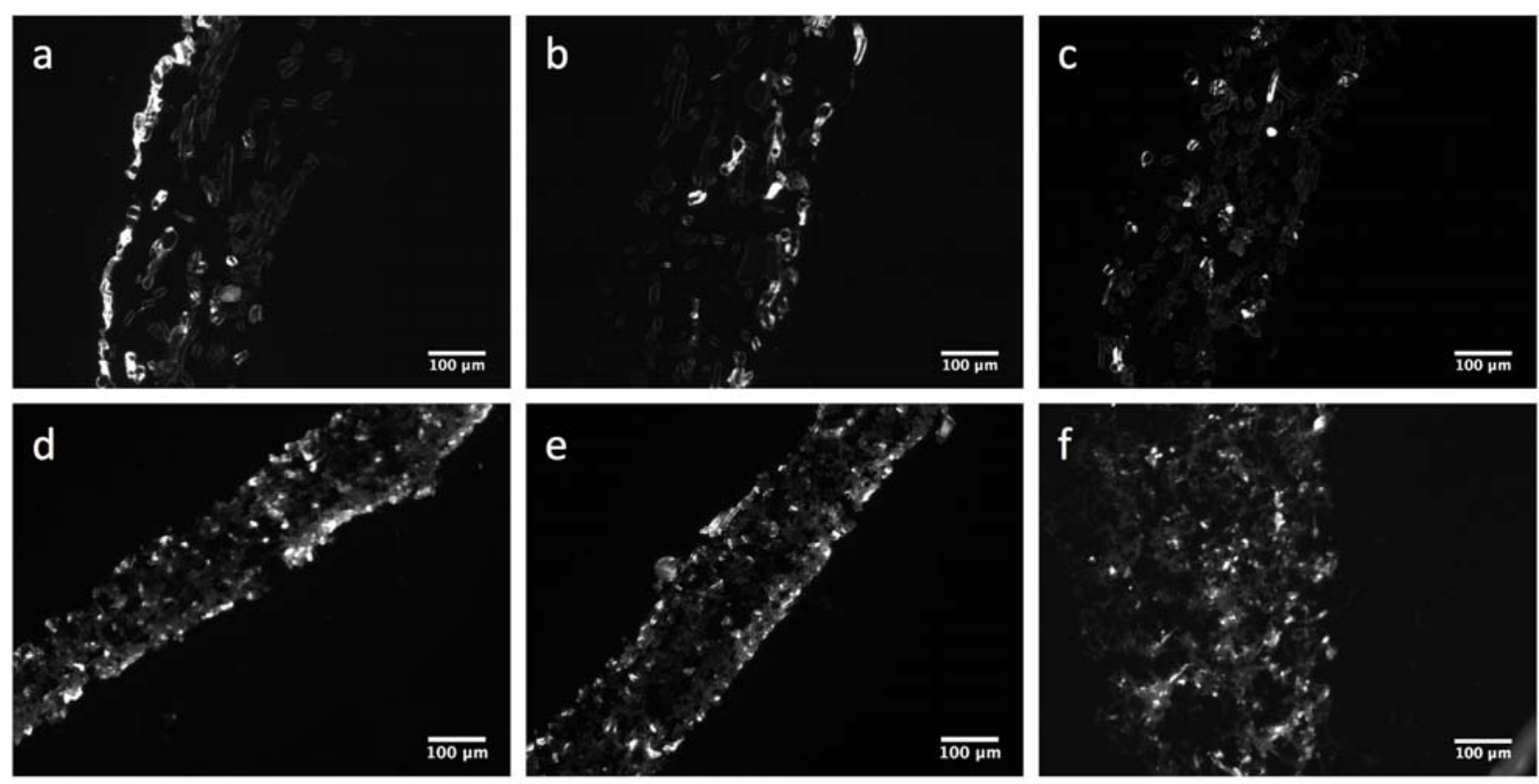

g

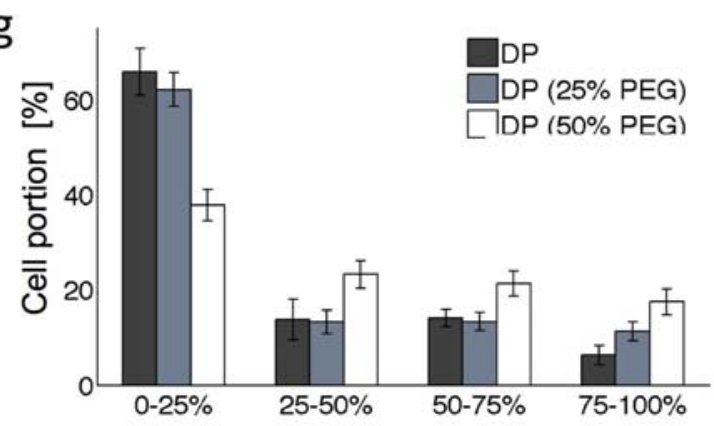

h

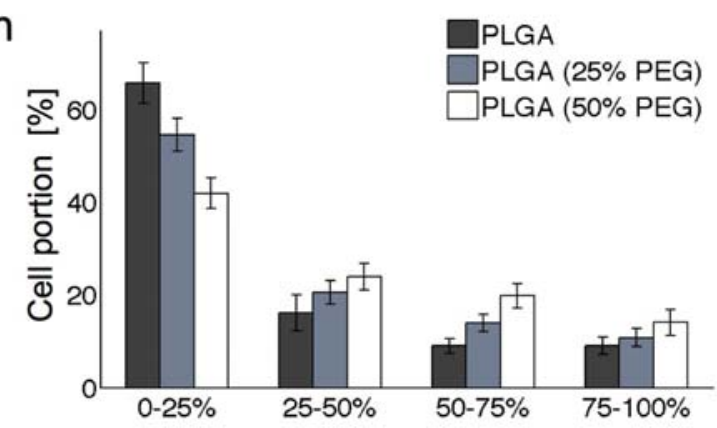

Fig. 11. Infiltration depth of NIH-3T3 fibroblasts into DP- and PLGA-3D-fiber-scaffolds produced with different porosities. 15,000 cells were seeded on fiber-fleeces produced with DP or PLGA with 0, 25 and 50\% PEG and cultivated for $14 \mathrm{~d}$. Fluorescent images of $8 \mu \mathrm{m}$ cryosections of DP (a-c) and PLGA (d-f) 3D-fiber-scaffolds produced with different PEG ratios ( $0 \%$ in $\mathbf{a}$ and $\mathbf{d}, 25 \%$ in $\mathbf{b}$ and $\mathbf{e}$, and $50 \%$ in $\mathbf{c}$ and $\mathbf{f}$ ) are presented and analyzed for cell infiltration. The effect of scaffold porosity on cell infiltration was compared between DP-scaffolds (g) and PLGAscaffolds (h). A deeper cell infiltration was found in more porous scaffolds.

Table 2: Mechanical properties of different DegraPol scaffolds. Values represent mean values and standard deviations. No values for yield elongation and stress are available for the aligned scaffolds in the transverse direction.

\begin{tabular}{ccccc}
\hline Scaffold properties & diameter & diameter & diameter & $\mathrm{P}$ \\
& $2.79 \mu \mathrm{m}$ & $4.51 \mu \mathrm{m}$ & $7.79 \mu \mathrm{m}$ & \\
\hline Young's Modulus & 1.73 & 2.02 & 2.15 & \\
[MPa] & \pm 0.19 & \pm 0.31 & \pm 0.40 & \\
Yield elongation & 8.17 & 8.83 & 10.17 & 9. \\
{$[\%]$} & \pm 0.76 & \pm 0.76 & \pm 0.77 &
\end{tabular}

Table 3: Mechanical properties of different PLGA scaffolds. Values represent mean values and standard deviations. No values for yield elongation and stress are available for the aligned scaffolds in the transverse direction.

\begin{tabular}{ccccc}
\hline \multirow{2}{*}{ Scaffold properties } & diameter & diameter & diameter & $\mathrm{P}$ \\
& $2.06 \mu \mathrm{m}$ & $4.14 \mu \mathrm{m}$ & $6.56 \mu \mathrm{m}$ & 79.64 \\
\hline Young's Modulus & 28.11 & 71.13 & \pm 5.86 \\
[MPa] & \pm 2.99 & \pm 13.78 & 4.17 \\
Yield elongation & 3.80 & 4.20 & \pm 0.65 \\
{$[\%]$} & \pm 0.30 & \pm 0.87 & \\
\hline
\end{tabular}




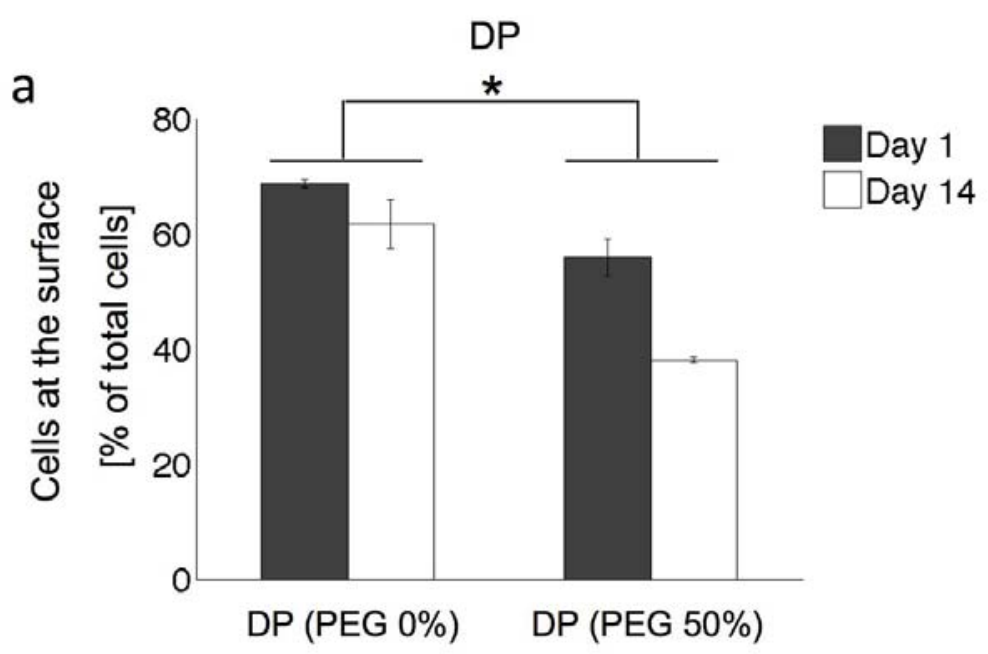

Fig. 12. Influence of porosity and culturing time on cell infiltration into fibrous DP- and PLGA-3D- fiber-scaffolds. The number of cells found in the outermost regions of the scaffolds ([0-25\%] of the scaffold's thickness) was compared after 1 and 14 days. 3D-fiberscaffolds were produced with plain DP (a) and PLGA (b) or co-spun with 50\% PEG. 15,000 cells were seeded and cultivated for 14 days whereas 100,000 cells were seeded and cultivated for one day. Mean values were compared by a 2-way ANOVA analysis and statistically significant differences $(p<0.05)$ were found for both parameters scaffold composition and time of culture.

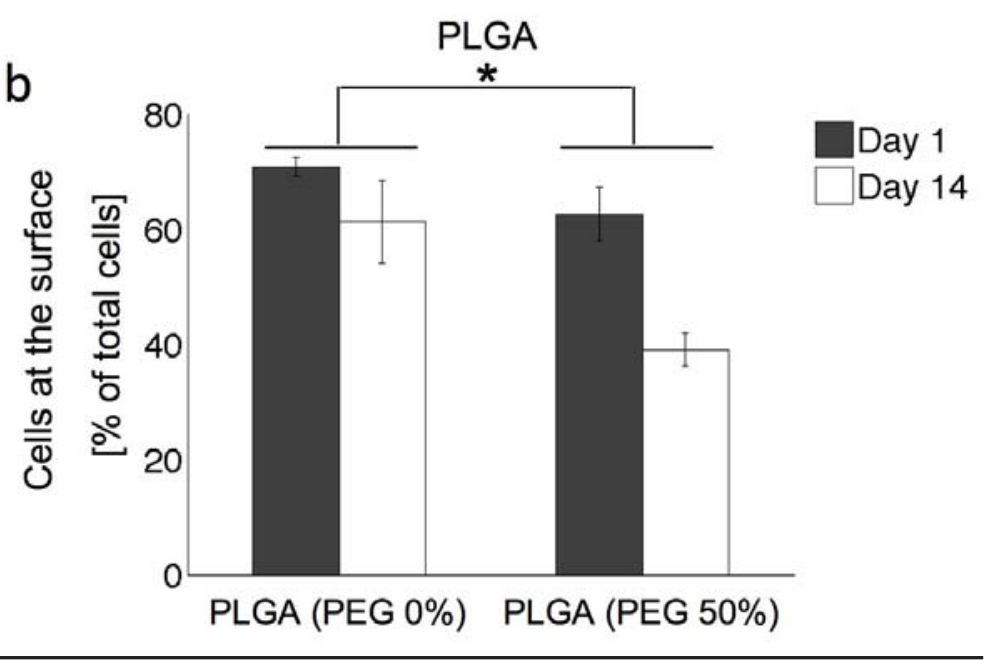

cell migration during the culture period. Therefore 100,000 cells were seeded on DP- and PLGA-scaffolds produced with $0 \%$ PEG and 50\% PEG, respectively and were analyzed after 1 day of culture. This condition was compared to 15,000 cells cultured for 14 days on similarlyproduced scaffolds. The percentage of cells found at the surface of the scaffolds compared to the total number of cells was determined after 1 and 14 days (Fig. 12). For all scaffolds more cells were found in the outermost regions of the scaffolds after 1 day of culture but infiltration was increased in scaffolds produced with 50\% PEG; in detail: for DP at day $1,69 \pm 1 \%$ of the cells were found at the surface of the scaffold produced without PEG whereas only $56 \pm 3 \%$ of the cells on the scaffolds produced with $50 \%$ PEG (Fig. 12a). Similarly, on PLGA scaffolds, $71 \pm 2 \%$ of the cells were detected in the outermost region of the scaffold produced without PEG at day 1 while there were $63 \pm 5 \%$ on the PLGA scaffolds produced with $50 \%$ PEG (Fig. 12b). After 14 days of cultivation the differences in infiltration into dense and more porous scaffolds was strongly enhanced. For DP produced without PEG, $62 \pm 4 \%$ cells were found on the surface (Fig. 12a) whereas only $38 \pm 0.4 \%$ were found at the surface for DP-scaffolds produced with $50 \%$ PEG. Similar findings were found for PLGA: $61 \pm 7 \%$ were at the surface of the scaffold whereas when PLGA-scaffolds were produced with $50 \%$ PEG only
$39 \pm 3 \%$ were detected (Fig. 12b), suggesting that cell infiltration relates to the porosity of the fibrous scaffold and depends on the cultivation time suggesting a combination between better initial seeding and enhanced cell migration during time of culture.

\section{Discussion}

\section{Characterization of DP and PLGA fiber structures}

This study aimed to produce and characterize Degrapol ${ }^{\circledR}$ (DP) and poly(lactic-co-glycolic acid) (PLGA) fibers with defined fiber diameters and orientation as well as 3D-fiber fleeces with increased porosity to improve cell infiltration. To compare DP- to PLGA-fibers, effects of electrospinning parameters on fiber diameter and orientation were studied and correlations were observed. So far not described in the literature was that fiber orientation increases with reduced flow rate and a larger working distance. This diminishes the flow rate and leads to thinner fibers, which contain less solvent and therefore harden faster. Harder fibers are less prone to bending, resulting in better aligned fibers. Increasing the working distance will increase the traveling time of the fiber which will dry and harden and deposit more aligned on the collector mandrel. Moreover, increasing the working distance for a constant force 
(applied voltage) leads to a decrease in traveling velocity of the fiber. This velocity and its fluctuations are then smaller compared to the mandrel's velocity, which can explain why the resulting fibers show better alignment. Moreover the fiber diameter increased when the collecting mandrel's velocity was reduced. Some of our observations confirmed earlier studies: in that the fiber diameter increased with increasing working distance (Baker et al., 2006) and an increase in flow resulted in smaller diameter fibers (Kidoaki et al., 2006) as well as when collected with a higher mandrel velocity (Matthews et al., 2002). All these relations indicate that production of controlled fiber diameters and orientation of the fibers require different and opposing electrospinning conditions as conditions leading to larger fiber diameters, led to reduced alignment of the fibers and vice versa. As fiber diameter and alignment cannot be adjusted independently from each other, all electrospinning parameters have to be finely tuned in order to be able to produce fibers with defined properties. Understanding and control of these parameters allowed reproducible production of DP- and PLGA-fibers with comparable diameters and orientation.

\section{Mechanical properties of the fibrous scaffolds}

Young's moduli of the scaffolds were shown to depend on the polymer that they were composed of, but interestingly it was also found to be dependent on the scaffold morphology, confirming findings already reported (Boland et al., 2001; Baker et al., 2008; Choi et al., 2008; Stylianopoulos et al., 2008; Aviss et al., 2010). The Young's modulus increased slightly with the fiber diameter for thin PLGA fibers composing the scaffolds while it decreased in scaffolds with increased porosity. Less porous scaffolds have more interconnected fibers that contribute to mechanical strength, while the correlation with the fiber diameter might be explained by the fact that scaffolds with thinner fibers have weaker junctions probably leading to decreased mechanical properties. Additionally, aligned scaffolds show higher elastic properties along the fiber direction compared to the transverse direction and random scaffolds (SEM images of random and aligned scaffolds tested for mechanical properties are shown in Fig. 6). Therefore, variations of the scaffold's morphology induce changes in the mechanical properties of the final constructs. As emphasized by the study of Kumbar et al. (2008a), mechanical properties of the electrospun scaffolds are highly dependent of the polymer of choice. Therefore in order to meet a specific biomedical application, it is crucial to choose a relevant polymer. The studies indicate that DegraPol's modulus is comparable to native human hollow tissues having a relatively low Young's modulus such as carotid artery (0.4 MPa) and femoral artery (0.8 MPa) (Brum et al., 2010), bladder (0.25 MPa) (Dahms et al., 1998). PLGA has a Young's modulus much closer to stiffer tissue such as tendon and ligaments (13-111 MPa) (Abousleiman et al., 2008; Noyes and Grood, 1976). Additionally, DP as well has a much higher yield elongation compared to PLGA (about $8-10 \%$ compared to $2-4 \%$ in PLGA, respectively. These findings confirm previous published studies (Riboldi et al., 2005; Van de Velde and
Kiekens, 2002). However, the elastic properties make DegraPol an excellent candidate for tissues encountering deformations (i.e., blood vessels or hollow organs).

\section{Control of scaffold porosity}

When 3D-scaffolds were produced with conventional electrospinning, cell infiltration was found to be very limited and cells did not penetrate deeper than $50 \mu \mathrm{m}$ into mixed poly $\varepsilon$-caprolactone/collagen 1:1 nanofiber scaffolds (Srouji et al., 2008). However, when scaffolds were produced with larger porosity increased cell infiltration in vitro and in vivo was observed (Leong et al., 2009). For these reasons DP- and PLGA-scaffolds with increased porosity were produced by co-electrospinning with various ratios of water-soluble PEG that could be removed easily. Removal of PEG was confirmed by fluorescence images, SEM images of cross sections of the fibrous scaffolds and by mass loss analysis of the composite scaffolds. For all scaffolds a mass loss corresponding to the removed PEG fraction was observed.

\section{Cell infiltration into porous scaffolds}

When NIH-3T3 cells were seeded on DP- and PLGAscaffolds with different porosities, several observations were made: initial cell adhesion did not vary significantly with porosity of the scaffold or with the chemistry of the used polymer and cell proliferation did not significantly change between different scaffold porosities, however, an increased proliferation rate was always observed on PLGAcompared to DP-scaffolds. All the samples were coated with collagen I before cell seeding, suggesting that the scaffold surface accessible for cells was similar on both scaffolds. An explanation for the difference in cell proliferation might be, that due to different chemical compositions of DP and PLGA protein adhesion is altered or modified as protein adsorption strongly depends on surface properties such as the surface energy, wettability, and surface charge (Jiao and Cui, 2007; Kumbar et al., 2008 b). Another explanation would be different mechanical properties of the polymers. Many studies have shown the importance of the substrate stiffness on cell fate, influencing their differentiation, adhesion, expression and metabolism (Chen et al. 2010; Nemir and West, 2010; Wang et al., 2000). Wang et al. reported that 3 T3 broblasts cultivated on $14 \mathrm{kPa}$ poly-acrylamide gels proliferated 2and 4- fold faster compared to cells cultivated on $4.7 \mathrm{kPa}$ gels after 24 and $48 \mathrm{~h}$ (Wang et al., 2000). In this study, we found that PLGA-electrospun scaffolds have a Young's Modulus about 30 times higher than DP-scaffolds; these findings might explain the differences in cell proliferation on DP and PLGA scaffolds.

After 14 days of culture, cell infiltration into DP- and PLGA-scaffolds produced with different porosities was shown to follow similar trends for both polymers. The infiltration was strongly improved when scaffolds were spun with $50 \mathrm{wt} \%$ space holder PEG. In plain DP- or PLGA-scaffolds more than $60 \%$ of the cells remained in the outermost region of the scaffold, while less than $10 \%$ of the cells were found infiltrated. In contrast, cell distribution throughout the section of the scaffolds was 
much more homogeneous in scaffolds that were produced with higher porosity suggesting that in higher porous scaffolds initial cell seeding is improved in addition to better cell infiltration during the cultivation period. The here described study confirms results described for scaffolds with similar porosities, prepared with different polymers such as poly( $\varepsilon$-caprolactone) as a permanent polymer and poly(ethylene oxide) as water-soluble polymer. That study investigated infiltration of mesenchymal stem cells that was strongly increased in more porous scaffolds (Baker et al., 2008). Moreover the study performed by Leong et al. provides good hopes regarding cell infiltration and vascularization into electrospun scaffolds with increased porosity in vivo. Although the initial cell seeding was found to be enhanced in scaffolds with increased porosity, time is an important factor for cell migration towards the inside of a scaffold. Leong et al. showed time dependency of cell infiltration in vivo with $0 \%, 80 \%$ and $100 \%$ cell infiltration into highly porous electrospun scaffolds after 0, 14 and $28 \mathrm{~d}$ after implantation. It has been shown that high initial cell densities improve subsequent tissue formation (Holy et al., 2000; Carrier et al., 2002) and uniformity of the seeding is related to the uniformity of newly formed tissue (IshaugRiley et al., 1998; Kim et al., 1998). In addition, time can be an issue for patients in need of soft tissue substitutes, and, it appears not only from this study that increasing the initial cell seeding number night not be sufficient for getting a homogeneously populated scaffold.

Summarizing, it can be said that co-spinning between non water-soluble and different ratios of water-soluble polymers has major advantages compared to cryoelectrospinning with respect to feasibility and control of scaffold porosity. The pores produced by co-spinning are very homogeneous as opposed to formation of large and heterogeneous pores with cryo-electrospinning. The here used technique allows to control the porosity and interconnectivity of pores, by changing the ratios of the permanent to the water-soluble polymers thus also varying the pore quantity; both will influence the success of an implant for tissue engineering by allowing a better cell infiltration and homogeneous distribution throughout the scaffold.

\section{Conclusion}

DP- and PLGA- fibers and 3D-fiber-fleeces were produced under defined conditions and tested for cell attachment, proliferation and infiltration, respectively. It could be shown that fiber diameter and orientation as well as scaffold porosity depend on the electrospinning conditions, and that fibers with different fiber diameters from different polymers can be produced in a controlled and reproducible manner. Mechanical testing of both polymers revealed that PLGA was much stiffer than DP ( 30 fold) and had a greater tensile yield. The elastic properties were found to be mainly dependent on the scaffold morphology (fiber alignment and porosity).

Infiltration studies were performed on 3D-fiber-fleeces with varying porosities and it was shown that cell infiltration depths and cell distribution within the scaffold was related to the scaffold porosity but independent of the polymer. Moreover, even though initial cell infiltration was increased for scaffolds with higher porosity, cell infiltration was observed to be time dependent, indicating that cells populate the scaffolds with time. The combination of increased porosity scaffolds with dynamic cell seeding methods might be a promising option for optimized cellularization of scaffolds.

Due to its mechanical properties, DegraPol can be envisioned for graft development of soft tissue requiring higher elasticity such as blood vessels or bladder. However, PLGA being much stiffer, and having a limited yield elongation, might be more suitable for ligament substitutes.

\section{Acknowledgments}

The authors would like to thank ab medica spa, Lainate, Italy for kindly providing DegraPol ${ }^{\circledR}$ and for a scientific fellowship for V. M.

\section{References}

Abousleiman RI, Reyes Y, McFetridge P, Sikavitsas V (2008) The human umbilical vein: A novel scaffold for musculoskeletal soft tissue regeneration. Artif Organs 32: 735-742.

Andrady AL (2008) Science and Technology of Polymer Nanofibers. J. Wiley \& Sons Inc.

Aviss KJ, Gough JE, Downes S (2010) Aligned electrospun polymer fibres for skeletal muscle regeneration. Eur Cell Mater 19: 193-204.

Baker BM, Gee AO, Metter RB, Nathan AS, Marklein RA, Burdick JA, Mauck RL (2008) The potential to improve cell infiltration in composite fiber-aligned electrospun scaffolds by the selective removal of sacrificial fibers. Biomaterials:29: 2348-2358.

Baker BM, Mauck RL (2007) The efect of nanofiber aignment on the maturation of engineered meniscus constructs. Biomaterials 28: 1967-1977.

Baker SC, Atkin N, Gunning PA, Granville N, Wilson K, Wilson D, Southgate J (2006) Characterization of polystyrene scaffolds for three-dimensional in vitro Biological Studies. Biomaterials:27: 3136-3146.

Bashur CA, Dahlgren LA, Goldstein AS (2006) Effect of fiber diameter and orientation on fibroblast morphology and proliferation on electrospun poly(D,L-lactic-coglycolic acid) meshes. Biomaterials 27: 5681-5688.

Boland ED, Matthews JA, Pawlowski KJ, Simpson DG, Wnek GE, Bowlin GL (2004) Electrospinning collagen and elastin: Preliminary vascular tissue engineering. Front Biosci 9: 1422-1432.

Boland ED, Wnek GE, Simpson DG, Pawlowski KJ, Bowlin GL (2001) Tailoring tissue engineering scaffolds using electrostatic processing techniques: A study of poly(glycolic acid) electrospinning. J Macromol Sci-Pure Appl. Chem A38: 1231-1243.

Brizzola S, de Eguileor M, Brevini T, Grimaldi A, Congiu T, Neuenschwander P, Acocella F (2009) 
Morphologic features of biocompatibility and neoangiogenesis onto a biodegradable tracheal prosthesis in an animal model. Interact Cardiovasc Thorac Surg 8: 610-614.

Brum J, Balay G, Bia D, Benech N, Ramos A, Armentano R, Negreira C (2010) Improvement of Young modulus estimation by ultrasound using static pressure steps. Physics Procedia 3: 1087-1094.

Carrier RL, Rupnick M, Langer R, Schoen FJ, Freed LE, Vunjak-Novakovic G (2002) Perfusion improves tissue architecture of engineered cardiac muscle. Tissue Eng 8: 175-188.

Chen DC, Avansino JR, Agopian VG, Hoagland VD, Woolman JD, Pan S, Ratner BD, Stelzner M (2006) Comparison of polyester scaffolds for bioengineered intestinal mucosa. Cells Tissues Organs 184: 154-165.

Chen WL, Likhitpanichkul M, Ho A, Simmons CA (2010) Integration of statistical modeling and high-content microscopy to systematically investigate cell-substrate interactions. Biomaterials 31: 2489-2497.

Choi JS, Lee SJ, Christ GJ, Atala A, Yoo JJ (2008) The influence of electrospun aligned poly( $\varepsilon$-caprolactone)/ collagen nanofiber meshes on the formation of self-aligned skeletal muscle myotubes. Biomaterials 29: 2899-2906.

Dahms SE, Piechota HJ, Dahiya R, Lue TF, Tanagho EA (1998) Composition and biomechanical properties of the bladder acellular matrix graft: Comparative analysis in rat, pig and human. Br J Urol 82: 411-419.

Danielsson C, Ruault S, Simonet M, Neuenschwander P, Frey P (2006) Polyesterurethane foam scaffold for smooth muscle cell tissue engineering. Biomaterials 8: 1410-1415.

Holy CE, Shoichet MS, Davies JE (2000) Engineering three-dimensional bone tissue in vitro using biodegradable scaffolds: Investigating initial cell-seeding density and culture period. J Biomed Mater Res 51: 376-382.

Ishaug-Riley SL, Crane-Kruger GM, Yaszemski MJ, Mikos AG (1998) Three-dimensional culture of rat calvarial osteoblasts in porous biodegradable polymers. Biomaterials 19: 1405-1412.

Jiao YP, Cui FZ (2007) Surface modification of polyester biomaterials for tissue engineering. Biomed Mater 2: R24-37.

Katti DS, Robinson KW, Ko FK, Laurencin CT (2004) Bioresorbable nanofiber-based systems for wound healing and drug delivery: optimization of fabrication parameters. J Biomed Mater Res B Appl Biomater 70: 286-296.

Kidoaki S, Kwon IK, Matsuda T (2005) Mesoscopic spatial designs of nano- and microfiber meshes for tissueengineering matrix and scaffold based on newly devised multilayering and mixing electrospinning techniques. Biomaterials 26: 37-46.

Kidoaki S, Kwon IK, Matsuda T (2006) Structural features and mechanical properties of in situ-bonded meshes of segmented polyurethane electrospun from mixed solvents. J Biomed Mater Res 76B: 219-229.

Kim BS, Putnam AJ, Kulik TJ, Mooney DJ (1998) Optimizing seeding and culture methods to engineer smooth muscle tissue on biodegradable polymer matrices. Biotechnol Bioeng 57: 46-54.
Kim K, Yu M, Zong X, Chiu J, Fang D, Seo YS, Hsiao BS, Chu B, Hadjiargyrou M (2003) Control of degradation rate and hydrophilicity in electrospun non-woven poly(D,L-lactide) nanofiber scaffolds for biomedical applications. Biomaterials 24: 4977-4985.

Kumbar SG, James R, Nukavarapu SP, Laurencin CT (2008a) Electrospun nanofiber scaffolds: Engineering soft tissues. Biomed Mater 3: 034002.

Kumbar SG, Nukavarapu SP, James R, Nair LS, Laurencin CT (2008b) Electrospun poly(lactic acid-coglycolic acid) scaffolds for skin tissue engineering. Biomaterials 29: 4100-4107.

Lendlein A, Colussi M, Neuenschwander P, Suter UW (2001) Hydrolytic degradation of phase-segregated multiblock copoly(ester-urethane)s containing weak links. Macromol Chem Phys 202: 2702-2711.

Lendlein A, Neuenschwander P, Suter UW (1998) Tissue-compatible multiblock copolymers for medical applications, Controllable in degradation rate and mechanical properties. Macromol Chem Phys 199: 27852796.

Leong MF, Chian KS, Mhaisalkar PS, Ong WF, Ratner BD (2009) Effect of electrospun poly(D,L-lactide) fibrous scaffold with nanoporous surface on attachment of porcine esophageal epithelial cells and protein adsorption. J Biomed Mater Res A 89: 1040-1048.

Mano JF, Silva GA, Azevedo HS, Malafaya PB, Sousa RA, Silva SS, Boesel LF, Oliveira JM, Santos TC, Marques AP, Neves NM, Reis RL (2007) Natural origin biodegradable systems in tissue engineering and regenerative medicine: Present status and some moving trends. J R Soc Interface 4: 999-1030.

Matthews JA, Wnek GE, Simpson DG, Bowlin GL (2002) Electrospinning of collagen nanofibers. Biomacromolecules:3: 232-238.

McClure MJ, Sell SA, Simpson DG, Walpoth BH, Bowlin GL (2011) A three-layered electrospun matrix to mimic native arterial architecture using polycaprolactone, elastin, and collagen: A preliminary study. Acta Biomater 6: 2422-2433.

Milleret V, Simonet M, Bittermann AG, Neuenschwande P, Hall H (2009) Cyto- and hemocompatibility of a biodegradable 3D-scaffold material designed for medical applications. J Biomed Mater Res B Appl Biomater 91: 109-121.

Nemir S, West JL (2010) Synthetic materials in the sudy of cell response to substrate rigidity. Ann Biomed Eng 38: 2-20.

Neuenschwander P (1994) Proceedings of the first Swiss conference on materials research for engineering systems, pp 209-215.

Noyes FR, Grood ES (1976) The strength of the anterior cruciate ligament in humans and rhesus monkeys. J Bone Joint Surg Am 58: 1074-1082.

Riboldi SA, Sadr N, Pigini L, Neuenschwander P, Simonet M, Mognol P, Sampaolesi M, Cossu G, Mantero S (2008) Skeletal myogenesis on highly orientated microfibrous polyesterurethane scaffolds. J Biomed Mater Res A 84: 1094-1101.

Riboldi SA, Sampaolesi M, Neuenschwander P, Cossu G, Mantero S (2005) Electrospun degradable 
polyesterurethane membranes: Potential scaffolds for skeletal muscle tissue engineering. Biomaterials 26: 46064615 .

Saad B, Keiser OM, Welti M, Uhlschmid GK, Neuenschwander P, Suter UW (1997) Multiblock copolyesters as biomaterials: In vitro biocompatibility testing. J Mater Sci Mater Med. 8: 497-505.

Saad B, Neuenschwander P, Uhlschmid GK, Suter UW (1999) New Versatile, Elastomeric, Degradable Polymeric Materials for Medicine. Int J Biol Macromol. 25:293-301.

Sell SA, McClure MJ, Garg K, Wolfe PS, Bowlin GL (2009) Electrospinning of collagen/biopolymers for regenerative medicine and cardiovascular tissue engineering. Adv Drug Deliv Rev 61: 1007-1019.

Simonet M, Schneider OD, Neuenschwander P, Stark WJ (2007) Ultraporous 3D polymer meshes by lowtemperature electrospinning: Use of ice crystals as a removable void template. Polymer Eng Sci 47: 2020-2026.

Srouji S, Kizhner T, Suss-Tobi E, Livne E, Zussman E (2008) 3-D nanofibrous electrospun multilayered construct is an alternative ECM mimicking scaffold. J Mater Sci: Mater Med 19: 1249-1255.

Stylianopoulos T, Bashur CA, Goldstein AS, Guelcher SA, Barocas VH (2008) Computational predictions of the tensile properties of electrospun fibre meshes: Effect of fibre diameter and fbre orientation. J Mech Behav Biomed Mater 1: 326-335.

Van de Velde K, Kiekens P (2002) Biopolymers: Overview of several properties and consequences on their applications. Polymer Testing 21: 433-442.

Wang HB, Dembo M, Wang YL (2000) Substrate flexibility regulates growth and apoptosis of normal but not transformed cells. Am J Physiol Cell Physiol 279: C1345-1350.

Xin X, Hussain M, Mao JJ (2007) Continuing differentiation of human mesenchymal stem cells and induced chondrogenic and osteogenic lineages in electrospun PLGA nanofiber scaffold. Biomaterials 28: 316-325.

Yasuda K, Inoue S, Tabata Y (2004) Influence of culture method on the proliferation and osteogenic differentiation of human adipo-stromal cells in nonwoven fabrics. Tissue Eng 10: 1587-1596.

\section{Discussion with Reviewer}

Reviewer I: What effect does the "coaxial jacket of chloroform saturated air" have on findings of the present work? It is reasonable to expect the presence of a high concentration of polymer solvent would greatly alter the electrospinning process, including outputs measured such as alignment and in particular, fiber diameter.

Authors: The coaxial jacket of chloroform prevents the polymer droplet of drying at the spinneret tip. Polymer droplets would lead to polymer accumulation followed by detachment and thus resulting in an inhomogeneous polymer jet. It has only a local effect at the spinneret tip, and the growing fiber travels through ambient air, which lets the chloroform evaporate. When produced with the chloroform jacket, the fibers don't appear more "wet" as compared as to when produced without.

Reviewer I: Because infiltration depends to a great extent on thickness of the scaffold, and scaffold thickness would likely change upon removal of water-soluble fibers, it is very important that thicknesses be reported for each group. Authors should also consider reporting migration distances rather than $\%$ thickness, as this would more strongly support their interpretation of the merits of a PEGcontaining scaffold.

Authors: You are correct. SEM images revealed that more porous scaffolds were thicker, thus not only more cells could enter into inner regions, but they had to migrate longer distances to reach those regions. It is difficult to find a good way to provide comparable absolute values e.g., of migration distance as we did an endpoint analysis. It is not clear whether the cells migrate along the fibers or along each other and if they take the 'fastest' and 'direct' way into the middle of the scaffold. Therefore, the position of the cells analyzed was calculated relatively to the scaffold thickness.

Reviewer I: Cell infiltration was assessed after 2 weeks, while proliferation was observed up to 4 weeks. Would assessment of infiltration over this longer duration maintain the same findings that increased PEG content increases infiltration? Alternatively, it may only result in faster infiltration. This will be more apparent if an extended culture duration is used.

Authors: Cell infiltration is obviously much quicker on scaffolds with higher porosity; it is very possible that full infiltration would occur also into denser scaffolds, but requiring much more time. In an implant perspective, it is crucial to have rapid cell infiltration, vascularization and innervations for being successful and this should appear in the early time after implantation of the implant. Otherwise the infiltrated cells will lack perfusion with gas and nutrients and undergo apoptosis.

Reviewer I: Is the quantification of cell proliferation at the scaffold surface a faithful measure when there are variations in cell ingress into the scaffold? Is not this a limitation?

Authors: The quantification of cell proliferation was done by AlamarBlue assay, which is a colored substrate solution for mitochondrial enzymes that is converted by living cells, added to the cell culture medium. It should be available to all the cells (even the ones within the scaffolds). Alamar blue is a very small dye that will also enter into the scaffold and reach cells within the scaffold, therefore not only cells on the scaffold surface are considered.

Reviewer I: Fiber morphologies, such as diameter, appear to be very dependent on PEG content. As others have shown, increased fiber diameters improve infiltration and increase pore size, calling into question the true mechanism underlying improvements seen in the current work. In other words, is the PEG truly acting as a porogen, or does it alter the electrospinning process in such a way that PLGA 
and DP fibers are enlarged, and this enlargement is responsible for improvements.

Authors: A change in fiber diameter leads to a change in pore size, but the overall porosity isn't affected (Baiguera et al., 2010). The porosity calculations (Fig.6), showing higher porosity for larger proportions of PEG, suggest that PEG is responsible for the increase in porosity. After removal of PEG larger pores remain and might be used for cell infiltration. Moreover, in our experimental setup where we spin PLGA and DP from one syringe and PEG from another syringe on the opposite site of the collector it is not very likely that both polymers form a larger diameter polymer fiber. Instead independent polymer fibers of the two polymers are produced. See also Fig. 3, where PLGA or DP fibers were labeled in red and PEG fibers in green, respectively. The fibers show a different deposition pattern and do not co-localize.

Reviewer I: It is one of the great challenges of scaffold design to create materials that can undergo recoverable, or elastic, deformations to the same extent as biologic tissues. The bladder for example, deforms by up to 50$70 \%$ elastically. What modifications could one make to improve scaffolds such as electrospun Degrapol ( 10\% yield strain) toward such a high elastic range?

Authors: This comment refers to one of the big advantages of DP. DegraPol can be produced in different grades, varying the ratio hard (PHB) and soft (PCL) segments and their synthesis. These different polymerizations lead to polymers with different mechanical properties, some with very high elasticity. Several compositions have been produced and compared by Hirt et al. (1996). The elasticity can be varied between 20-1250 MPa and covers most of biological tissues that might need to be replaced by tissue engineering approaches. Moreover, in vivo experiments have shown (Henry et al., 2007) that DP keeps its elasticity after implantation. This is in contrast to implanted PLGA that stiffens when exposed to watery environment (Stammen et al., 2001).

\section{Additional References}

Baiguera S, Del Gaudio C, Fioravanzo L, Bianco A, Grigioni M, Folin M (2010) In vitro astrocyte and cerebral endothelial cell response to electrospun poly $(\varepsilon-$ caprolactone) mats of different architecture. J Mater Sci Mater Med 21: 1353-1362.

Henry JA, Simonet M, Pandit A, Neuenschwander P (2007) Characterization of a slowly degrading biodegradable polyester-urethane for tissue engineering scaffolds. J Biomed Mater Res A 82: 669-679.

Hirt TD, Neuenschwander P, Suter UW (1996) Synthesis of degradable, biocompatible, and tough blockcoployesterurethanes. Macromol Chem Phys 197: 42534268.

Stammen JA; Williams S, Ku DN, Guidberg RE (2001) Mechanical properties of a novel PVA hydrogel in shear and unconfined compression. Biomaterials 22: 799-806. 